\title{
Investigation of Electrical and Photovoltaic \\ Properties of Au/n-Si Schottky diode with BOD-Z-EN Interlayer
}

\section{Ali Osman Tezcan}

Giresun University: Giresun Universitesi

\section{Serkan Eymur}

Giresun University: Giresun Universitesi

\section{Enis Taşcl}

Giresun University: Giresun Universitesi

\section{Mustafa Emrullahoğlu}

Izmir Institute of Technology: Izmir Yuksek Teknoloji Enstitusu

Nihat Tuğluoğlu ( $\nabla$ tugluo@gmail.com )

Giresun Universitesi https://orcid.org/0000-0001-9428-4347

\section{Research Article}

Keywords: Organic semiconductor, Schottky diode, Photodiode, BODIPY

Posted Date: February 19th, 2021

DOl: https://doi.org/10.21203/rs.3.rs-217283/v1

License: (c) (i) This work is licensed under a Creative Commons Attribution 4.0 International License.

Read Full License

Version of Record: A version of this preprint was published at Journal of Materials Science: Materials in Electronics on April 20th, 2021. See the published version at https://doi.org/10.1007/s10854-021-058867. 


\title{
Investigation of electrical and photovoltaic properties of $\mathrm{Au} / \mathrm{n}-\mathrm{Si}$ Schottky diode with BOD-Z-EN interlayer
}

\author{
Ali Osman Tezcan ${ }^{1}$, Serkan Eymur $^{1}$, Enis Taşc1 $^{2}$, Mustafa Emrullahoğlu ${ }^{3}$, Nihat Tuğluoğlu ${ }^{1, *}$ \\ ${ }^{1}$ Department of Energy Systems Engineering, Giresun University, Giresun, Turkey \\ ${ }^{2}$ Vocational School of Health Services, Giresun University, Giresun, Turkey \\ ${ }^{3}$ Department of Photonics, İzmir Institute of Technology, İzmir, Turkey \\ *Correspondence: nihat.tugluoglu@giresun.edu.tr
}

\begin{abstract}
4,4-Difluoro-4-bora-3a,4a-diaza-s-indacene (BODIPY) based BOD-Z-EN compound was used as an interfacial organic layer to fabrication of Au/BOD-Z-EN/n-Si/In diode. The electrical parameters of $\mathrm{Au} / \mathrm{BOD}-\mathrm{Z}-\mathrm{EN} / \mathrm{n}-\mathrm{Si} / \mathrm{In}$ diode such as ideality factor $(n)$, barrier height $\left(\Phi_{B}\right)$ and series resistance $\left(R_{s}\right)$ have been investigated through current-voltage $(I-V)$ studies at dark and under various illumination intensities to understand the effect of interlayer on the device properties. The values found for the $n$ varied from 2.33 to 1.55 and the $\Phi_{B}$ ranged from $0.86 \mathrm{eV}$ to $0.90 \mathrm{eV}$ as the illumination condition changed from dark to $100 \mathrm{~mW} / \mathrm{cm}^{2}$. Series resistance $\left(R_{s}\right)$ values calculated using Cheung's method were found to decrease with increasing illumination level. The forward bias $I$ - $V$ characteristics of the diode were explained by the space charge limited current (SCLC) theory. The main photovoltaic parameters such as open circuit voltage $\left(V_{o c}\right)$, short circuit current $\left(J_{s c}\right)$ and fill factor $(F F)$ were determined for various light intensity. The Au/BOD-Z-EN/n-Si/In diode exhibits a photovoltaic behavior with a $V_{o c}$ of $0.15 \mathrm{~V}$ and $J_{s c}$ of $0.01 \mathrm{~mA} / \mathrm{cm}^{2}$ under $100 \mathrm{mw} / \mathrm{cm}^{2}$. Also, photosensitivity and photoresponsivity properties of the diode were determined. These all results indicate that Au/BOD-Z$\mathrm{EN} / \mathrm{n}-\mathrm{Si} / \mathrm{In}$ device can be used as photosensor in optoelectronic applications.
\end{abstract}

Key words: Organic semiconductor, Schottky diode, Photodiode, BODIPY

\section{Introduction}

Organic materials have been intensively considered as alternatives to conventional inorganic materials in the manufacture of various types of electronics devices because of their several advantages such as low cost, ease of production processes, chemical stability and compatibility with large area applications [1-3]. It has been shown that the electrical and photoelectrical properties of metal-semiconductor (MS) contacts such as a barrier height and ideality factor can be easily improved with organic materials used as thin interfacial layer in MS structures. Many studies have reported that the organic film contacted with the inorganic semiconductor in MS contacts can affect the performance of these devices due to the change in the density of the interface states, saturation current, and diode resistance [2, 4-11]. Among the variety of organic compounds for the fabrication of organic-based optoelectronic devices, organic 
dyes stand out prominently due to their chemical tunability, band-gap improvement properties, high photoconductive features and diversity of chemical structures [12-18].

One of the most popular fluorescent dyes used in the literature over the past two decades is BODIPY (4,4-difluoro-4-bora-3a, 4a-diaza-s-indacene). Due to their excellent photophysical properties such as high absorption coefficient, fluorescence quantum efficiency and long excited state, BODIPY based pconjugated structures have been attractive in terms of development of organic semiconductors [19-21]. For these reasons, it is not unexpected that the BODIPY core is a remarkable fluorescent structure for various applications such as dye-sensitized solar cells, fluorescent molecular probes, and photovoltaics. Despite the interest in the excellent photophysical properties of BODIPY dyes, there are only a few studies characterizing the electronic parameters of Schottky diodes using BODIPY based compounds as an organic interfacial layer. For instance, Tataroglu et. al. synthesized BODIPY decorated thiophene compound and fabricated Al/p-Si/BDY-3T-BDY/Al diode [22]. They studied by using (photo)electrical properties of diode in detail by using $I-V, C / G-V$ characteristics. Ozcan et al. synthesized phthalocyanine-BODIPY conjugates to fabricate Al/BODIPY/p-Si/Al diode [23]. They studied electrical and photoresponse measurements showed that BODIPY based devices exhibit photodiode properties. Therefore, studies investigating the electrical and optical characterizations of BODIPY compounds are still needed to investigate possible potentials of using BODIPY compounds in optoelectronic applications. Based on these concerns, in this study, we synthesized is a highly pconjugated BODIPY derivative (BOD-Z-EN) according to literature [24] (Fig. 1). Then, we fabricated $\mathrm{Au} / \mathrm{BOD}-\mathrm{Z}-\mathrm{EN} / \mathrm{n}-\mathrm{Si} / \mathrm{In}$ structure. The electrical and photoelectrical properties of the device were investigated by means of illumination dependent $I-V$ measurements. The aim of this study is to investigate the effect of the BOD-Z-EN as an organic interfacial layer on main electronic parameters of device.

\section{Experimental Details}

\subsection{Synthesis of BOD-Z-EN compound}

The synthesis of the BOD-Z-EN, and intermediate compounds BODIPY and BOD-I are shown in Fig. 1. The all compounds were prepared according to published literature procedures [24]. The synthesis started with obtaining the BODIPY from the reaction of compound $\mathbf{1}$ and to in the presence of $\mathrm{BF}_{3}$. $\mathrm{Et}_{2} \mathrm{O}$. Iodination of BODIPY compound with iodosuccinimide gives BODIPY-I. Then, BODIPY-I reacted with [(Z)-3-methylpent-2-en-4-yn-1-ol] (3) according to a Sonogashira coupling conditions and BODZ-EN was obtained in a moderate yield. The structural characterization was confirmed by ${ }^{1} \mathrm{H}$ and ${ }^{13} \mathrm{C}$ spectroscopy. 


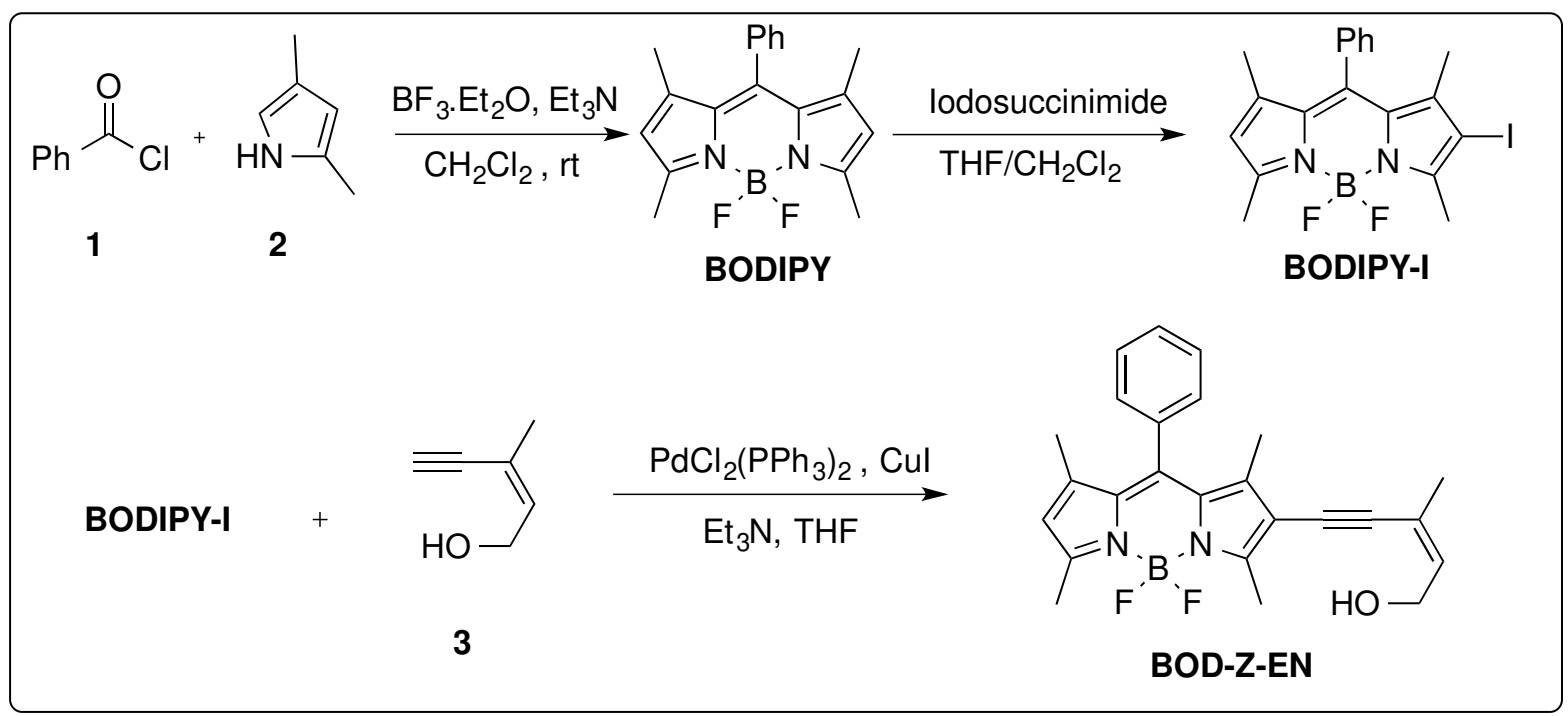

Fig. 1 Synthetic route to BOD-Z-EN

\subsection{Fabrication of Au/BOD-Z-EN/n-Si/In Diode}

Firstly, the wafer was chemically cleaned by using acetone and methanol. Later, the n-Si wafer was chemically cleaned using various chemical baths according to RCA cleaning procedure. To form ohmic contact, an indium metal (99.999\%) with a thickness of $100 \mathrm{~nm}$ was thermally evaporated onto the backside of the n-Si wafer at a pressure of $10^{-5} \mathrm{Torr}$, and then the wafers were annealed at $350{ }^{\circ} \mathrm{C}$ for 30 sec in $\mathrm{N}_{2}$ gas. Then, the solution of BOD-Z-EN was coated on the front surface of $n-S i$ wafer by spin coating technique with the $1200 \mathrm{rpm}$ for $1 \mathrm{~min}$. Finally, $150 \mathrm{~nm}$ Au metal was thermally evaporated through a shadow mask to form a rectifier contact on the organic layer. The thickness of the organic interface layer was estimated as $32.1 \mathrm{~nm}$ from high frequency capacitance data at strong accumulation regime. Schematic diagram of the Au/BOD-Z-EN/n-si/In diode is shown in Fig. 2. The $I-V$ characteristics of the diode were measured by using a Keithley 4200 SCS system in dark and under various illumination intensities.

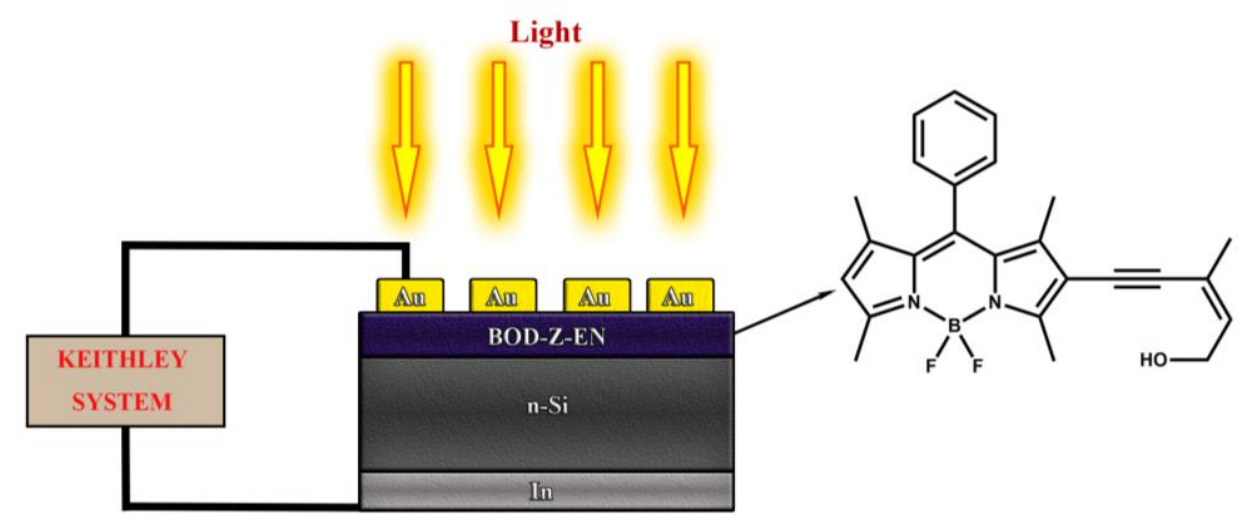

Fig. 2 Schematic structure of the Au/BOD-Z-EN/n-Si/In device 


\section{Results and discussion}

First of all, we performed density functional theory (DFT) calculations at the B3LYP/6-31G(d,p) level to investigate position and spatial distribution of the energy levels of highest occupied molecular orbital (HOMO) and lowest unoccupied molecular orbital (LUMO) that are responsible for the electronic properties of BOD-Z-EN $[25,26]$. The frontier molecular orbitals distributions in the ground state are shown in Fig. 3a. The computed HOMO and LUMO energy levels for BOD-Z-EN were found to be $-5.57 \mathrm{eV}$ and $-2.68 \mathrm{eV}$, respectively, which means that the HOMO-LUMO energy gap $(\Delta \mathrm{E})$ for the BOD-Z-EN is $2.79 \mathrm{eV}$. In the literature, the values of $\Delta \mathrm{E}$ for semiconductor materials were presented range from $0.5 \mathrm{eV}$ to $2.5 \mathrm{eV}$ [27]. Therefore, the calculated $\Delta \mathrm{E}$ value $(2.79 \mathrm{eV})$ shows that BOD-Z-EN can have a semiconducting behavior. Energy band diagram of Au/BOD-Z-EN/n-Si/In device is also given in Fig. 3b.

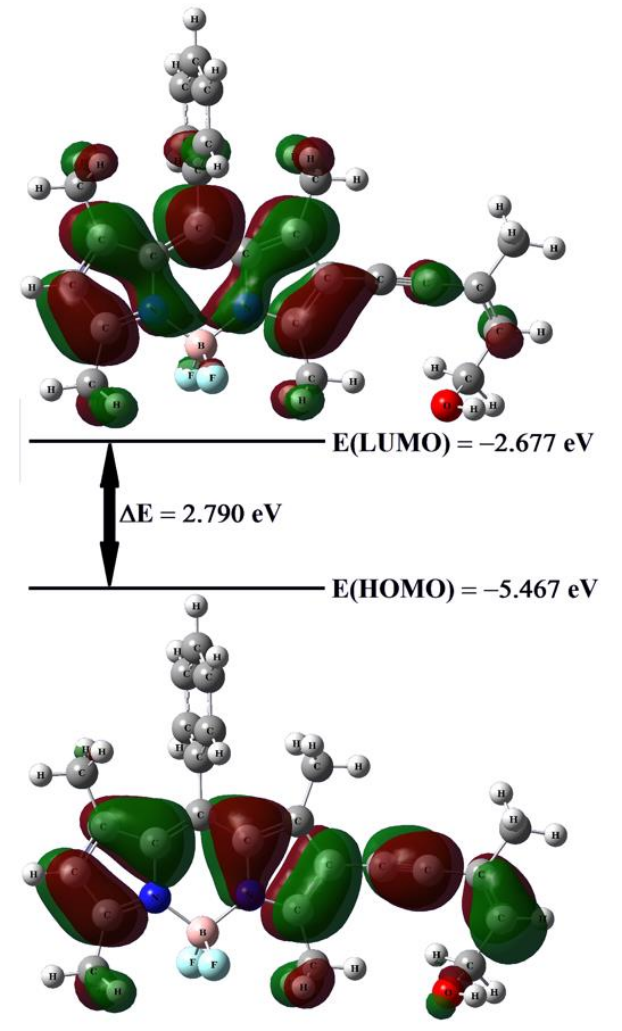

(a)

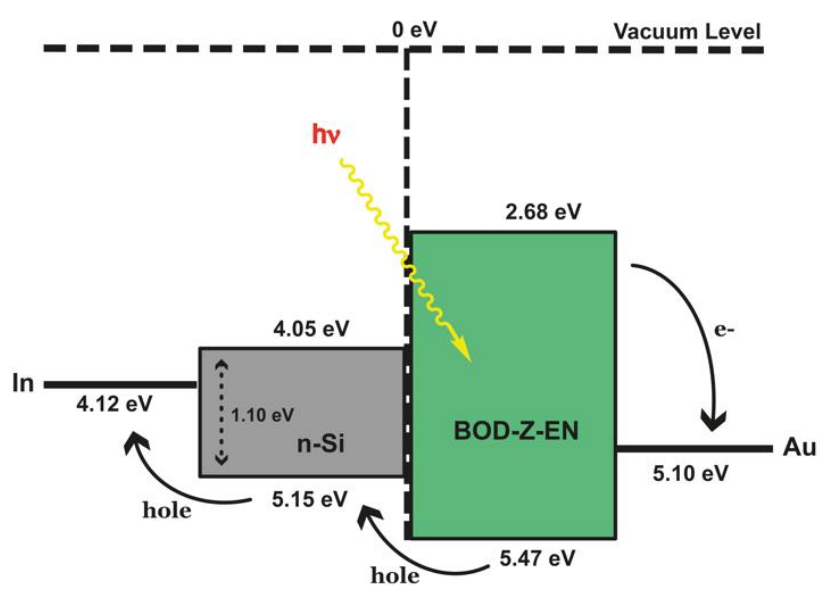

(b)

Fig. 3 (a) Computed HOMO/LUMO energy levels of BOD-Z-EN (b) Energy band diagram of Au/BODZ-EN/n-Si/In device

The behavior of the Schottky diode is known to be largely dependent on $I-V$ characteristics. For this reason, $\mathrm{Au} / \mathrm{BOD}-\mathrm{Z}-\mathrm{EN} / \mathrm{n}-\mathrm{Si} / \mathrm{In}$ diode was studied by means of the semi-logarithmic $I-V$ characteristics in dark and different illumination intensities. As seen in the Fig. 4, the fabricated device showed good 
rectification behavior with rectification ratio $\sim 100$ in dark and $\sim 8$ under $100 \mathrm{~mW} / \mathrm{cm}^{2}$. The rectification ratio for the device was found to be by dividing the forward current by the reverse current at $\mathrm{a} \pm 2 \mathrm{~V}$. When the $I$ - $V$ curves are examined in Fig. 4 , it is seen that the diode behaves like metal/semiconductor Schottky device in low voltage regime, obeying thermionic emission (TE). Therefore, the main electrical parameters, such as ideality factor $(n)$, barrier height $\left(\Phi_{B}\right)$ and saturation current $\left(I_{0}\right)$, were obtained by analysis of $I-V$ characteristic by using the TE theory $(\mathrm{V} \geq 3 \mathrm{kT} / \mathrm{q})$ given as $[3,28]$

$$
I=I_{0}\left[\exp \left(\frac{q\left(V-I R_{S}\right)}{n k T}\right)-1\right]
$$

and $I_{0}$ is gives as

$$
I_{0}=A A^{*} T^{2} \exp \left[-\frac{q \phi_{b}}{k T}\right]
$$

where $I R_{s}, k, T$, A and $A^{*}$ are, respectively, voltage drop across $R_{s}$ of the diodes, Boltzmann constant, temperature in Kelvin, Schottky contact area and the effective Richardson constant for $\mathrm{n}-\mathrm{Si}\left(A^{*}=112\right.$ $\mathrm{AK}^{-2} \mathrm{~cm}^{-2}$ ). When eqn (1) and (2) are arranged, the $n$ and $\Phi_{B}$ terms may be expressed as

$$
n=\frac{q}{k T} \frac{d V}{d(\ln I)}
$$

and

$$
\Phi_{b}=\frac{k T}{q} \ln \left(\frac{A A^{*} T^{2}}{I_{0}}\right)
$$

Thus, the value of $I_{o}$ can be taken from the straight-line intercept of the forward-bias $I-V$ curve at a voltage equal to zero. The value of $n$ can also be obtained from the slope of the linear region of the semilogarithmic $I-V$ plot. Additionally, $\Phi_{B}$ value can be calculated from the eqn (2). Estimated values of these $n, \Phi_{B}$ and $I_{o}$ values for Au/BOD-Z-EN/n-Si/In diode are listed in Table 1 . The $n$ value is theoretically equal to 1 for ideal diodes, and as seen in Table 1 , the $n$ values of Au/BOD-Z-EN/n-si/In diode for both in dark and under different light intensities were greater than unity as expected. This behavior is known as non-ideal diode characteristics. These higher $n$ values may be attributed to different reasons such as barrier inhomogeneity, existence of interface states and series resistance. As listed in Table 1, the values of $\Phi_{\mathrm{b}}$ and $n$ were found to be $0.86 \mathrm{eV}$ and 2.33, in dark, respectively. Under $100 \mathrm{~mW} / \mathrm{cm} 2$ illumination, $\Phi_{\mathrm{b}}$ and $n$ values changed to $0.90 \mathrm{eV}$ and 1.55 , respectively. It is seen that $n$ and $I_{o}$ values decrease with the increase in light intensity, while opposite trend is observed for $\Phi_{\mathrm{b}}$ values with increased light intensity. 


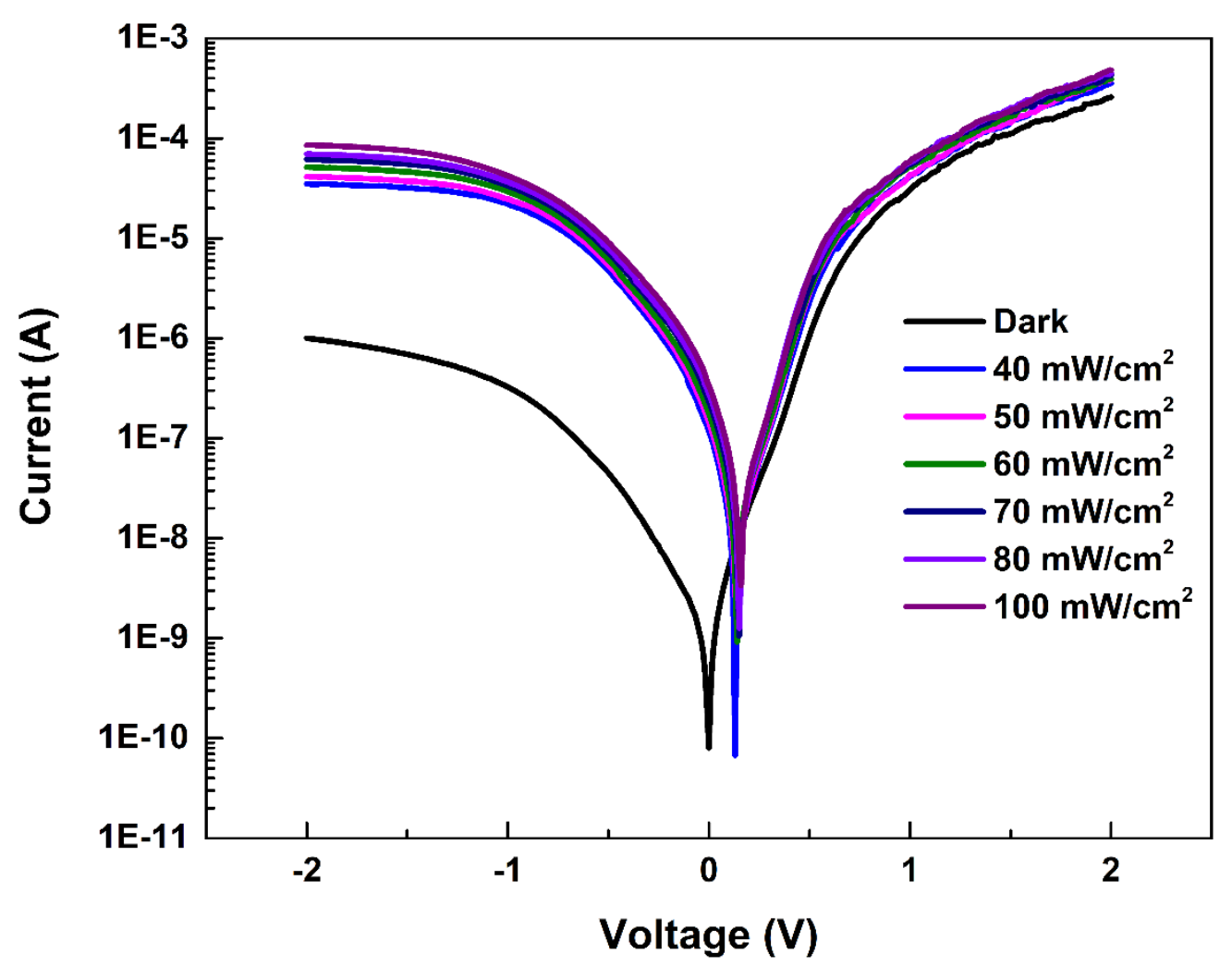

Fig. 4 The forward and reverse bias the $I-V$ characteristics of the Au/BOD-Z-EN/n-Si/In device

Table 1 Illumination intensity dependent values of $n, I_{0}$ and $\Phi_{b}$ obtained from $I$ - $V$ measurements

\begin{tabular}{ccccc}
\hline $\begin{array}{c}\text { Illumination intensity } \\
\left(\mathrm{mW} / \mathrm{cm}^{2}\right)\end{array}$ & $n$ & $I_{0}(\mathrm{~A})$ & $\Phi_{b}(\mathrm{eV})$ & $R s(\mathrm{k} \Omega)$ \\
\hline 0 & 2.33 & $9.84 \times 10^{-10}$ & 0.86 & 6.22 \\
40 & 2.04 & $5.90 \times 10^{-10}$ & 0.88 & 5.76 \\
50 & 2.01 & $5.71 \times 10^{-10}$ & 0.88 & 5.72 \\
60 & 1.86 & $5.09 \times 10^{-10}$ & 0.88 & 4.87 \\
70 & 1.73 & $3.71 \times 10^{-10}$ & 0.89 & 4.39 \\
80 & 1.64 & $2.85 \times 10^{-10}$ & 0.90 & 4.24 \\
100 & 1.55 & $2.48 \times 10^{-10}$ & 0.90 & 4.15 \\
\hline
\end{tabular}

In order to understand the dominant current transport properties of the Au/BOD-Z-EN/n-Si/In junction in the forward bias region, logarithmic plot of the $I-V$ curve was drawn. Three distinct charge transport mechanisms which have different slopes can be seen in Fig. 5. The slope of the region $1,-4.60<\ln V<$ -2.30 , close to unity. Since ohmic currents increase linearly with the voltage conduction mechanism is dominated by ohmic conduction in the region 1 . In the region $2,-2.21<\ln V<-1.43$, the slope is about 2.1, and the current follows the relationship I $\propto V^{2}$, the major conduction mechanism is space charge limited current (SCLC) $[3,28,29]$. At higher voltage level in the region 3 and $4,-1.14<\ln V$, the slopes 
of the were measured to be 6.1 and 3.9, and the current follows a power law $\left(I \propto V^{2}\right)$, the charge transport is governed by the trap-charge-limited current (TCLC) [3, 28, 29].

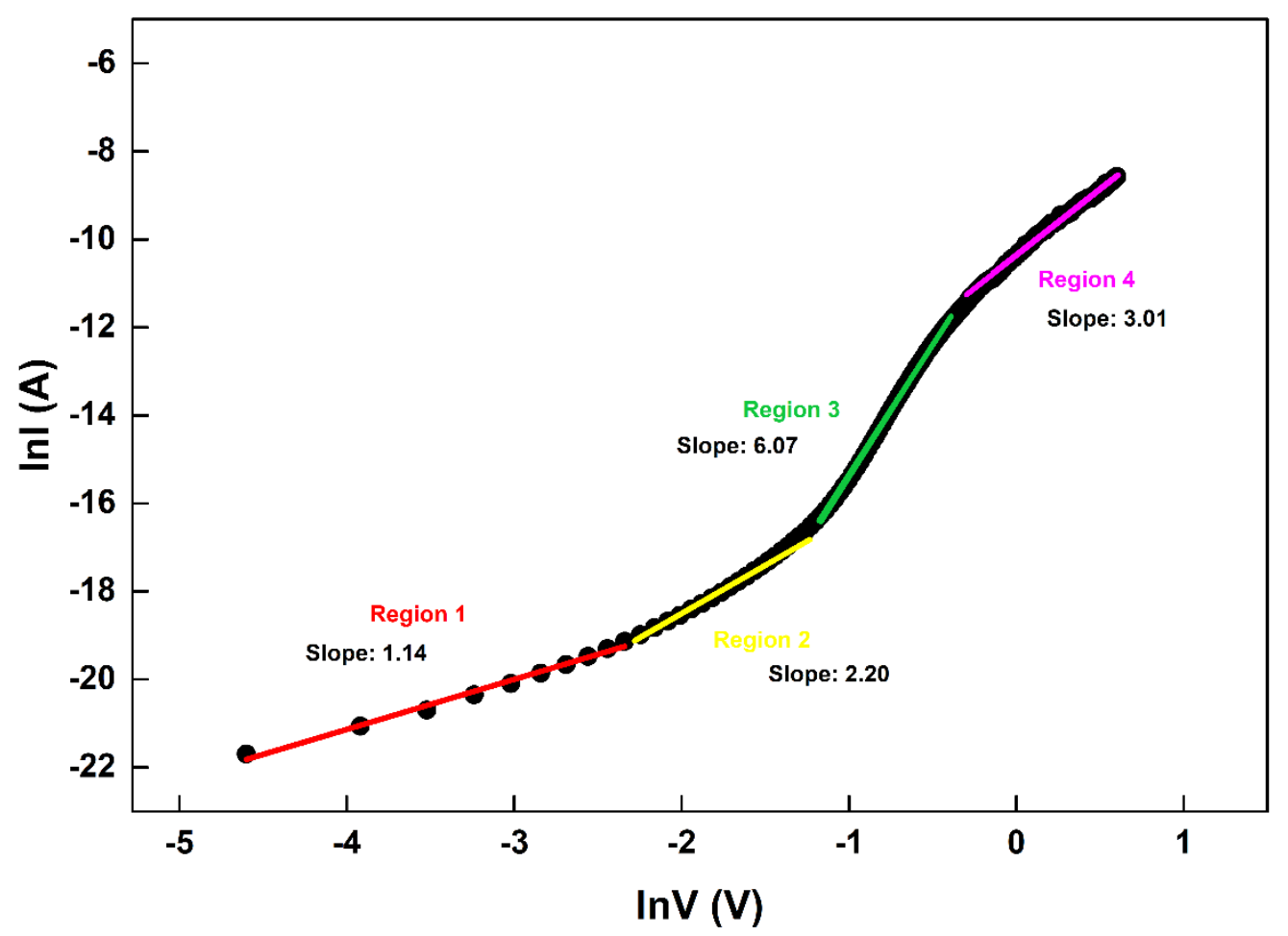

Fig. 5 The $\ln (I)$ versus $\ln (V)$ plot of the Au/BOD-Z-EN/n-Si/In device

To understand the electrical properties of the Schottky barrier diodes, the analysis of the effect of series resistance $\left(R_{s}\right)$ on diode parameters is also important. The values of $R_{s}$ can be easily obtained by Cheung method which is $H(I)$ function as follows [30]:

$$
H(I)=V-n \frac{k T}{q} \ln \left(\frac{I}{A A * T^{2}}\right)
$$

and

$$
H(I)=n \phi_{b}+I R_{S}
$$

Experimental $H(I)$ versus $I$ plots for dark and various illumination conditions shown in Fig. 6. In these curves, a linear region appears as expected and slope of $H(I)$ vs. $I$ curve directly yields $R_{s}$. The calculated $R_{s}$ values are listed in Table 1 . As seen, $R_{s}$ value was calculated as $6.22 \mathrm{k} \Omega$ and $4.15 \mathrm{k} \Omega$ for dark and $100 \mathrm{~mW} / \mathrm{cm}^{2}$, respectively. $R_{s}$ values decreased with increasing illumination level which may be attributed to the generation of free charge carriers by incident light absorption. 


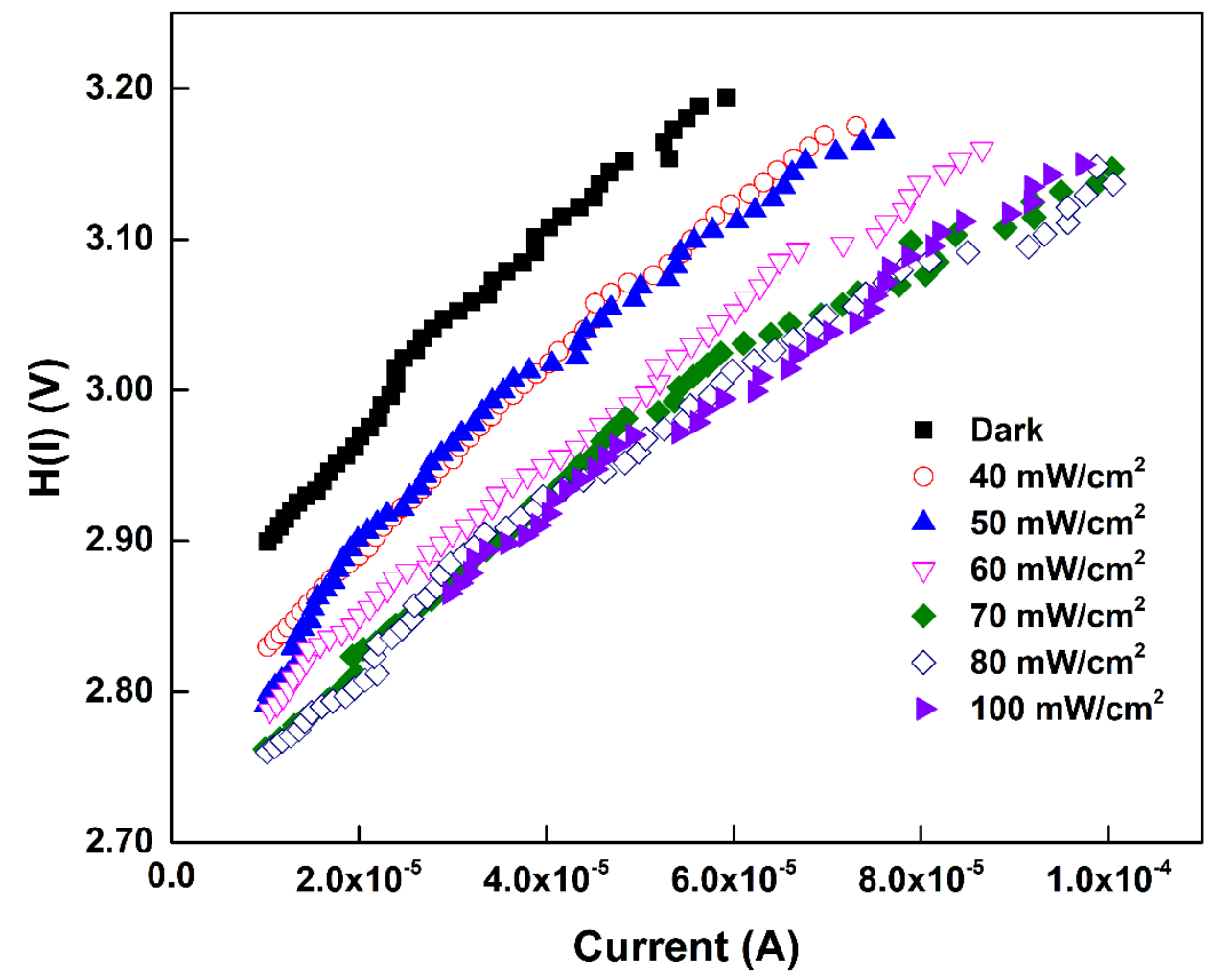

Fig. $6 H(I)$ vs $I$ plots for Au/BOD-Z-EN/n-Si/In device

The interface state density $\left(N_{s s}\right)$ in Schottky diodes is another import parameter that effect directly ideality factor and barrier height of the diode. The $N_{s s}$ dependence of the ideality factor and voltage is expressed by Card and Rhoderick as [29]

$$
N_{S S}(V)=\frac{1}{q}\left[\frac{\varepsilon_{i}}{\delta_{i}}(n(V)-1)-\frac{\varepsilon_{S}}{W_{D}}\right]
$$

where $\delta_{i}$ is the thickness of interface organic layer, $W_{D}$ is depletion region width, $\varepsilon_{s}$ and $\varepsilon_{i}$ are dielectric constant of semiconductor and interface, respectively. In n-type semiconductor, the relation between the energy of the interstate states $E_{s s}$ and bottom of the conduction band energy of semiconductor $\left(E_{c}\right)$ is given by

$$
E_{c}-E_{S S}=q\left(\Phi_{e}-V\right)
$$

where $\Phi_{e}$ is the effective barrier height and $q$ is the electron charge. Therefore, the $N_{s s}$ values of $\mathrm{Au} / \mathrm{BOD}-\mathrm{Z}-\mathrm{EN} / \mathrm{n}-\mathrm{Si} / \mathrm{In}$ device were calculated by using eqn (7) and (8). The values of $N_{s s}$ vs. $\left(E_{c}-E_{s s}\right)$ curves of the $\mathrm{Au} / \mathrm{BOD}-\mathrm{Z}-\mathrm{EN} / \mathrm{n}-\mathrm{Si} / \mathrm{In}$ diode for dark and under different illumination intensities are given in Fig 7. The $N_{s s}$ values of the diode obtained from the forward bias $I-V$ ranges from $2.69 \times 10^{12} \mathrm{~cm}^{-2} \mathrm{eV}^{-}$ ${ }^{1}$ to $7.87 \times 10^{11} \mathrm{~cm}^{-2} \mathrm{eV}^{-1}$ for dark and $2.25 \times 10^{12} \mathrm{~cm}^{-2} \mathrm{eV}^{-1}$ to $7.09 \times 10^{11} \mathrm{~cm}^{-2} \mathrm{eV}^{-1}$ for $100 \mathrm{~mW} \mathrm{~cm}{ }^{-2}$ illumination level. As seen in Fig. 7, $N_{s s}$ values show an exponential increase from the middle gap of $\mathrm{Si}$ to the bottom of the conduction band $\left(\mathrm{E}_{\mathrm{c}}\right)$. It is also seen that the values of $N_{s s}$ decrease with the increasing illumination intensity. These observations reveal that BOD-Z-EN, used as an organic interfacial layer, may act as passivated material in the device and causes decrease the magnitude of $N_{s s}$. 


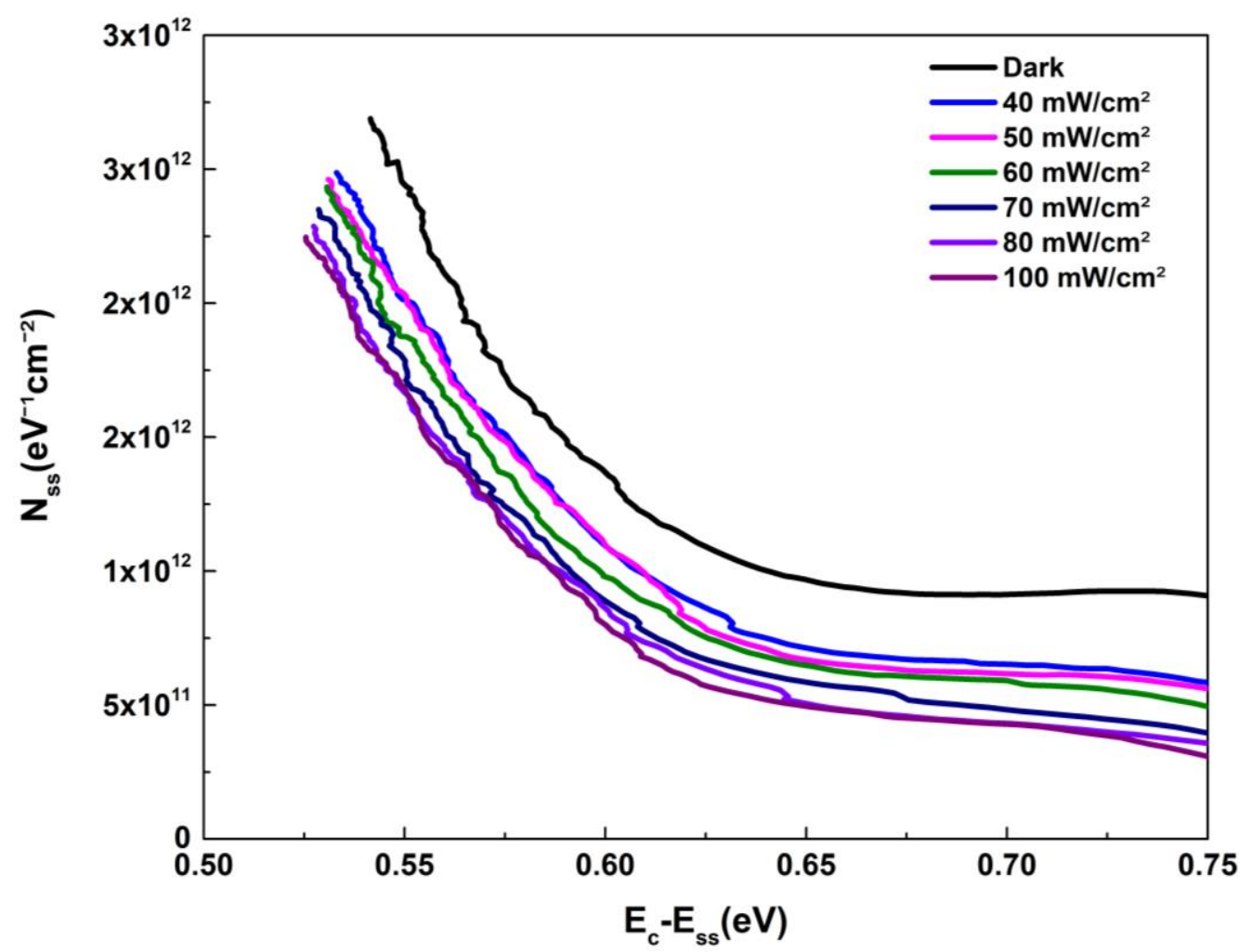

Fig. $7 N_{s s}$ distributions profile of the Au/BOD-Z-EN/n-Si/In diode

The $I-V$ characteristics of the Au/BOD-Z-EN/n-Si/In structure in dark and under various illumination levels, shown in Fig. 3, clearly demonstrate that Au/ BOD-Z-EN /n-Si/In device is highly light sensitive and the exhibits photovoltaic behavior. Therefore, as seen in Fig. 8, the current density-voltage $(J-V)$ characteristics of $\mathrm{Au} / \mathrm{BOD}-\mathrm{Z}-\mathrm{EN} / \mathrm{n}$-Si/In diode in dark and under different illumination intensities were drawn to determination of the main photodiode parameters. In Fig. 8, the point where the $I-V$ curve intersects the voltage axis gives the open circuit voltage $\left(V_{o c}\right)$ value. The point where the $I-V$ curve intersects the current axis at same region gives short circuit current $\left(J_{s c}\right)$ value. The values of maximum voltage $\left(V_{\max }\right)$ and maximum current $\left(I_{\max }\right)$ are found from the largest rectangle which can be drawn between the $I-V$ curve and coordinates of the Fig. 8. Also, the filled factor $(F F)$ and maximum power $\left(P_{\max }\right)$ values are expressed as

$$
F F=\frac{V_{\max } I_{\max }}{V_{o c} I_{s c}}
$$

and

$$
P_{\max }=I_{\max } V_{\max }
$$

According to this, as tabulated in Table 2, the characteristic photodiode parameters include $V_{o c}, J_{s c}, V_{\max }$, $I_{\max }, F F$ and $P_{\max }$ were calculated to obtain more information about the photovoltaic performance of the diode. As listed in Table 2, the increase in the values of $V_{o c}$ and $J_{s c}$ with increasing in illumination intensity can be attributed to the increasing electron conductivity of organic interfacial layer. The $F F$ 
values also increase with increasing of the illumination level until it reached to 18.29 under $60 \mathrm{~mW} / \mathrm{cm}^{2}$ illumination level and then it decreases may be because of the ohmic losses in the device and large series resistance of the organic layer.

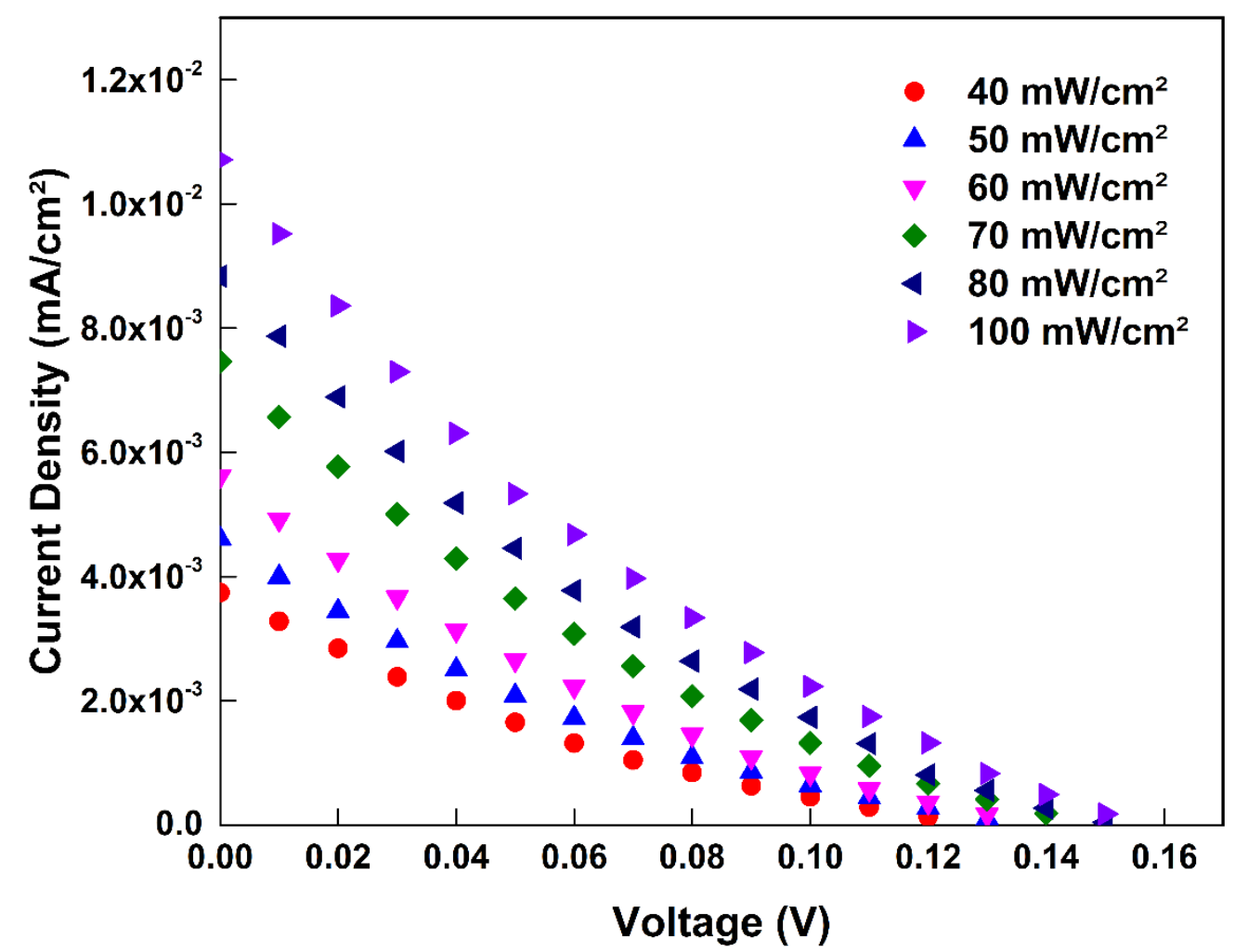

Fig. 8 The current density-voltage $(J-V)$ characteristics of Au/BOD-Z-EN/n-Si/In device in dark and under different illumination levels.

Table 2 The photodiode parameters of the Au/BOD-Z-EN/n-Si/In device under various illumination levels

\begin{tabular}{ccccccc}
\hline Power $\left(\mathrm{mW} / \mathrm{cm}^{2}\right)$ & $V_{o c}(\mathrm{~V})$ & $J_{s c}\left(\mathrm{~mA} / \mathrm{cm}^{2}\right)$ & $V_{\max }(\mathrm{V})$ & $I_{\max }(\mathrm{mA})$ & $F F$ & $P_{\max }\left(\mathrm{mW} / \mathrm{cm}^{2}\right)$ \\
\hline 40 & 0.13 & 0.004 & 0.05 & 0.0016 & 16.97 & $8.25 \times 10^{-5}$ \\
50 & 0.13 & 0.005 & 0.05 & 0,0021 & 17.35 & $10.4 \times 10^{-5}$ \\
60 & 0.13 & 0.006 & 0.06 & 0.0022 & 18.29 & $13.3 \times 10^{-5}$ \\
70 & 0.14 & 0.008 & 0.06 & 0.0031 & 17.69 & $18.4 \times 10^{-5}$ \\
80 & 0.15 & 0.009 & 0.06 & 0.0037 & 17.10 & $22.6 \times 10^{-5}$ \\
100 & 0.15 & 0.01 & 0.06 & 0.0046 & 17.46 & $28.0 \times 10^{-5}$ \\
\hline
\end{tabular}

In order to further understand the photosensitivity behavior of Au/BOD-Z-EN/n-Si Schottky diode, the photosensitivity, characterized as eqn (11), was plotted against illumination intensity $(P)$ at $-2 \mathrm{~V}$. As seen 
in Fig. 9, Au/BOD-Z-EN/n-Si Schottky diode exhibits a good photosensitivity behavior. The photosensitivity $(S)$ of the diode were calculated using following equation [31, 32]

$$
S(\%)=\frac{I_{p h}}{I_{\text {dark }}} \times 100
$$

where $I_{p h}$ is the generated photocurrent $\left(I_{p h}=I_{\text {light }}-I_{\text {dark }}\right)$ and $I_{\text {dark }}$ is the dark current.

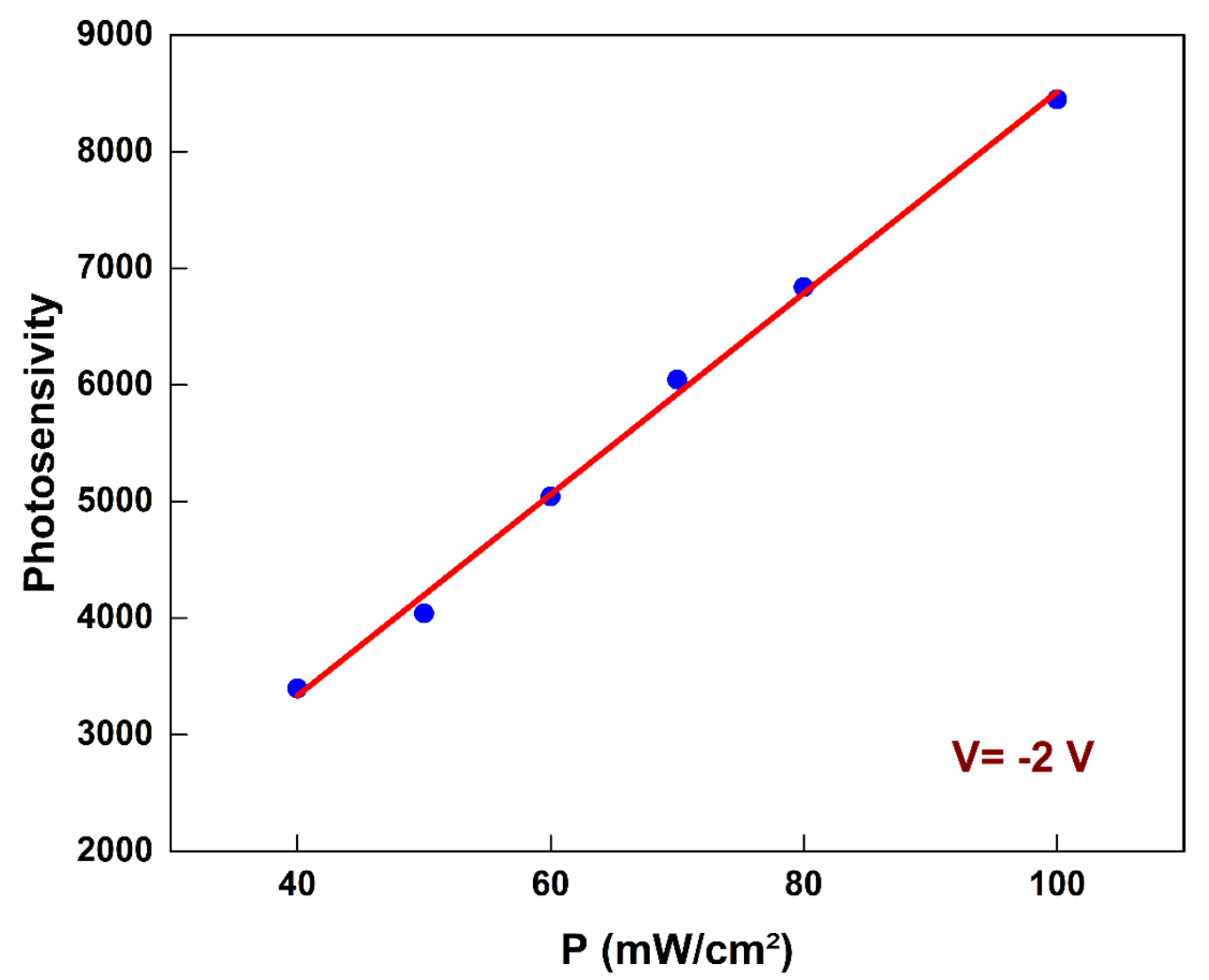

Fig. 9 Plot of photosensitivity vs. $P$ for the Au/BOD-Z-EN/n-Si/In diode.

The photoresponsivity $(R)$ of the diode which also known as the light responsivity is another important photodiode parameter. The photoresponsivity $(R)$ were determined through the relation $[31,32]$

$$
R=\frac{I_{p h}}{P \cdot A}
$$

where $P$ is the illumination intensity and $A$ is the diode area. Fig. 10 shows the illumination dependent $R-V$ characteristics of Au/BOD-Z-EN/n-Si diode. The increase in the photoresponsivity values with the increasing illumination intensity indicates that the Au/BOD-Z-EN/n-Si diode can be used as an inorganic/organic photodiode. 


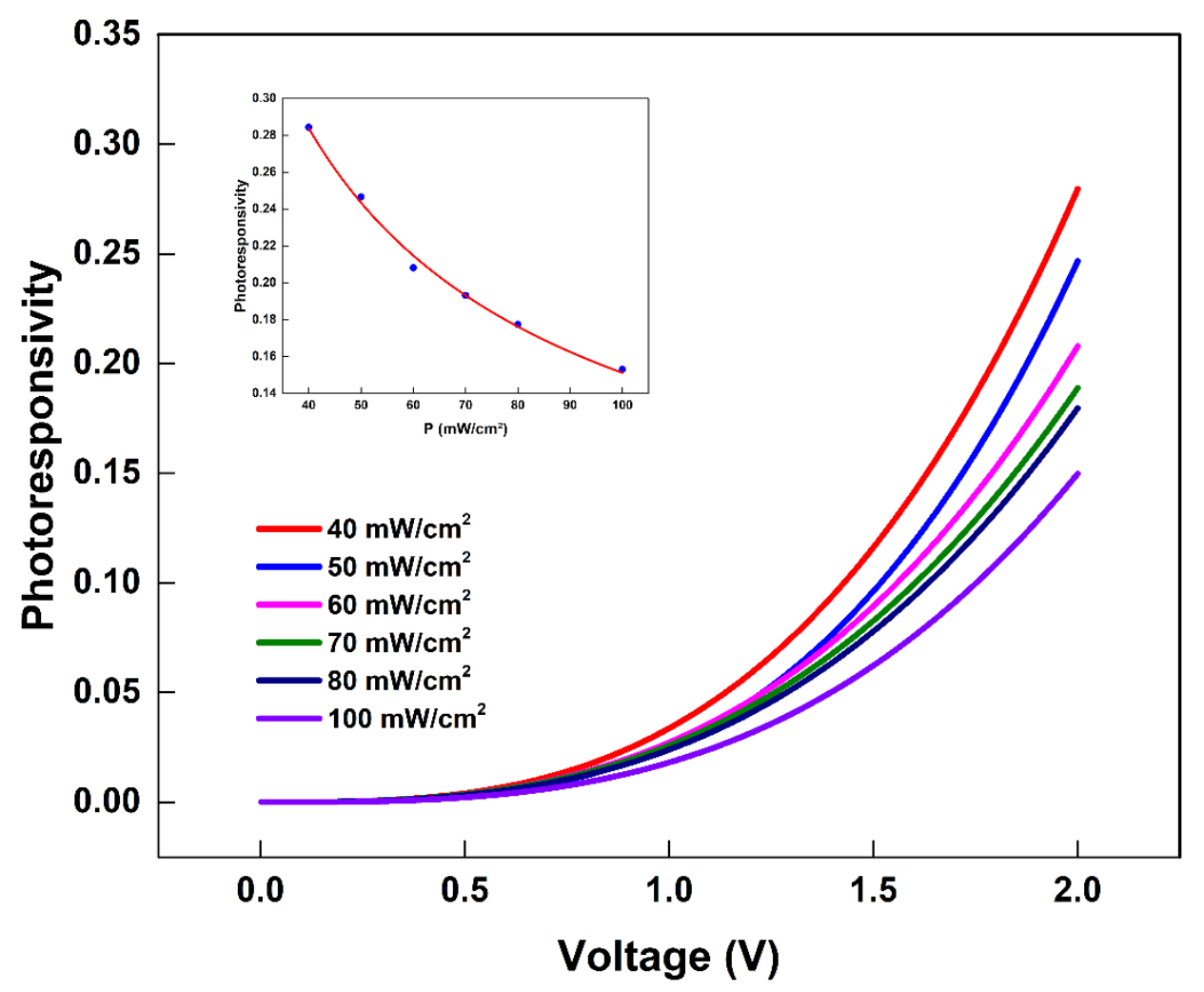

Fig. $10 R-V$ plot of Au/BOD-Z-EN/n-Si/In Schottky diode under various illumination intensity

To understand the photoconduction mechanism of Au/BOD-Z-EN/n-Si/In Schottky diode the relation between $\ln I_{p h}$ and $\ln P$ was studied. Since the photocurrent depends on the photogeneration rate the variation of the photocurrent against illumination intensity is given by

$$
I_{p h}=\gamma P^{\beta}
$$

where $\gamma$ value is a constant, $\beta$ is an exponent which is determined from the slope of the len $I_{p h}$ vs. $\ln P$ plot and $P$ is the intensity of illumination. Plot of $\ln I_{p h}$ vs. $\ln P$ of Au/BOD-Z-EN/n-Si/In diode is given in Fig. 11. As seen, the photocurrent increases almost linearly with increasing illumination intensity. The $\beta$ value which describes whether the process of recombination is monomolecular or bimolecular was found as 1.01 reflects bimolecular recombination mechanism [33, 34]. 


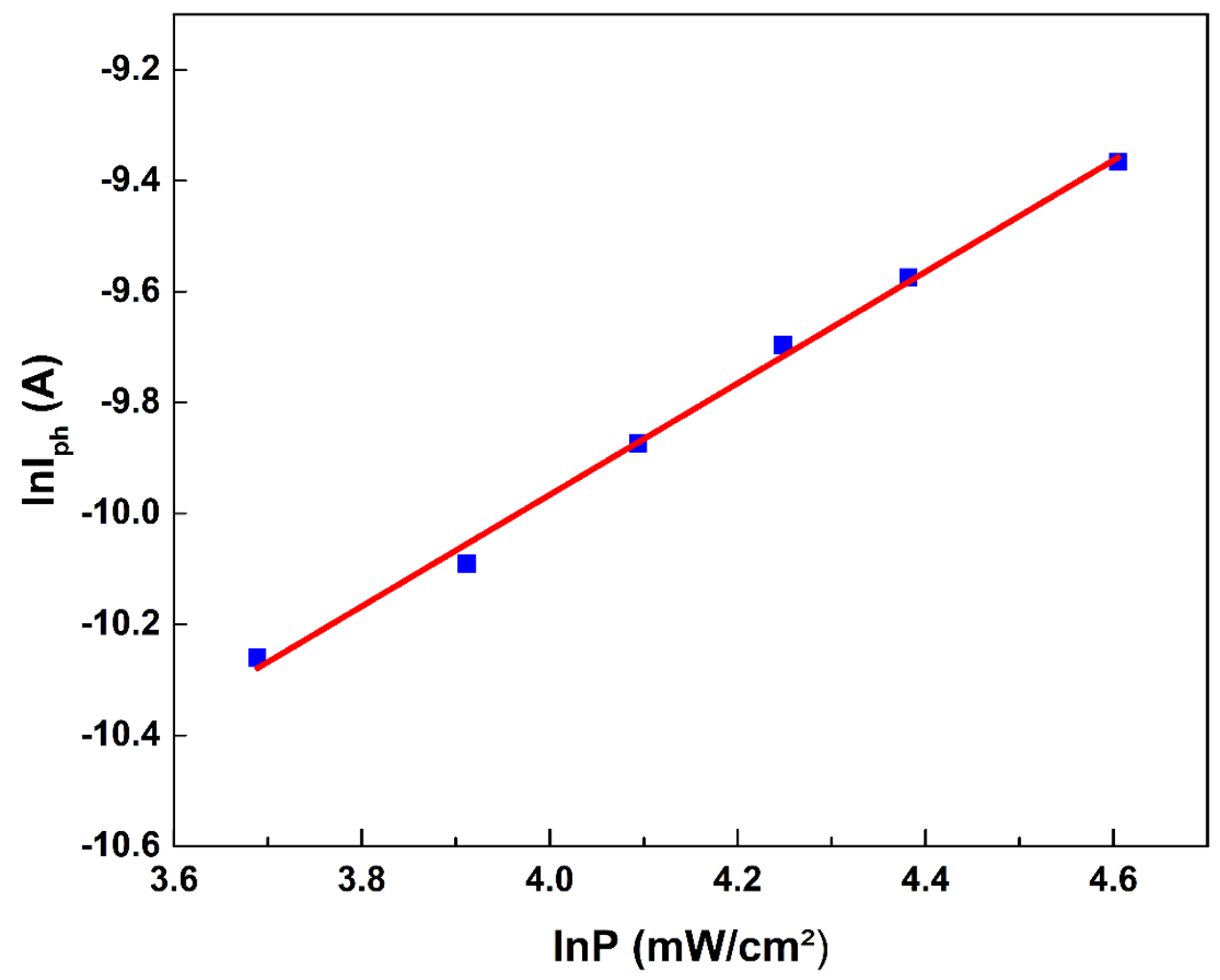

Fig. $11 \ln \mathrm{I}_{\mathrm{ph}}-\ln \mathrm{P}$ plot of the Au/BOD-Z-En/n-Si/In diode

\section{Conclusion}

In summary, BOD-Z-EN was synthesized according to literature. Besides, HOMO/LUMO band gaps of BOD-Z-EN were calculated by DFT/B3LYP/6-311G(d,p) method. Au/BOD-Z-EN/n-Si/In Schottky diode were fabricated to show potential semiconductor device applications of BODIPY based organic compounds. The main diode parameters such as ideality factor, barrier height and series resistance have been determined from $(I-V)$ studies at the dark and under various illumination levels. All obtained results showed that it was found that the barrier height and ideality factor of the device showed strong illumination dependencies, in which the barrier height increases while the ideality factor decreases with increasing illumination intensity. $R_{S}$ values obtained by Cheung's method also found to be decrease with increasing illumination level which may be due to the generation of free charge carriers. Furthermore, the main photovoltaic parameters such as open circuit voltage, short circuit current and fill factor were also determined from $I-V$ measurements under various illumination levels. It was observed that the $\mathrm{Au} / \mathrm{BOD}-\mathrm{Z}-\mathrm{EN} / \mathrm{n}-\mathrm{Si} / \mathrm{In}$ diode shows a photovoltaic behavior with a $V_{o c}$ of $0.15 \mathrm{~V}$ and $I_{s c}$ of $0.01 \mathrm{~mA} \mathrm{~cm}{ }^{-2}$ under $100 \mathrm{~mW} / \mathrm{cm}^{2}$. All these results reveal that Au/BOD-Z-EN/n-Si/In device can be used in the applications of electrical and photoelectrical devices.

\section{Declaration of Competing Interest}

The authors report no declarations of interest. 


\section{Acknowledgements}

The authors would like to thank Dr. Halil GÖKÇE from Giresun University for his help in discussion of computational studies.

\section{References}

[1] W. Brütting, Physics of Organic Semiconductors, (Wiley-VCH, Weinheim, 2012)

[2] W. Hu, Organic Optoelectronics, (Wiley-VCH, Weinheim, 2013)

[3] S. M. Sze, K. K. Ng, Physics of Semiconductor Devices, (Wiley-Interscience, Hoboken, N.J., 2007)

[4] A. Eroglu, S. Demirezen, Y. Azizian-Kalandaragh, S. Altindal, Journal of Materials Science-Materials in Electronics 31, 14466 (2020)

[5] A. G. Imer, O. Karaduman, F. Yakuphanoglu, Synth. Met. 221, 114 (2016)

[6] F. M. Jin, Z. S. Su, B. Chu, P. F. Cheng, J. B. Wang, et al., Scientific Reports 6, (2016)

[7] O. Pakma, S. Cavdar, H. Koralay, N. Tugluoglu, O. F. Yuksel, Physica B 527, 1 (2017)

[8] I. S. Yahia, H. Y. Zahran, F. H. Alamri, M. A. Manthrammel, S. AlFaify, A. M. Ali, Physica B 543, 46 (2018)

[9] M. Yildirim, A. Erdogan, O. F. Yuksel, M. Kus, M. Can, et al., Journal of Materials Science-Materials in Electronics 30, 10408 (2019)

[10] O. F. Yuksel, N. Tugluoglu, H. Safak, Z. Nalcacigil, M. Kus, S. Karadeniz, Thin Solid Films 534, 614 (2013)

[11] S. Karadeniz, B. Baris, O. F. Yuksel, N. Tugluoglu, Synth. Met. 168, 16 (2013)

[12] K. Hunger, Industrial Dyes: Chemistry, Properties, Applications, (Wiley-VCH, Weinheim, 2002)

[13] T. D. Kim, K. S. Lee, Macromol. Rapid Commun. 36, 943 (2015)

[14] I. V. Klimovich, L. I. Leshanskaya, S. I. Troyanov, D. V. Anokhin, D. V. Novikov, et al., J. Mater. Chem. C 2, 7621 (2014)

[15] J.-F. Morin, J. Mater. Chem. C 5, 12298 (2017)

[16] R. Stalder, J. Mei, K. R. Graham, L. A. Estrada, J. R. Reynolds, Chem. Mater. 26, 664 (2014)

[17] C. Wang, X. Zhang, W. Hu, Chem. Soc. Rev. 49, 653 (2020)

[18] C. Wang, Z. Zhang, Y. Wang, J. Mater. Chem. C 4, 9918 (2016) 
[19] Y. Q. Fan, J. J. Zhang, Z. Y. Hong, H. Y. Qiu, Y. Li, S. C. Yin, Polymers 13, 30 (2021)

[20] D. Ho, R. Ozdemir, H. Kim, T. Earmme, H. Usta, C. Kim, Chempluschem 84, 18 (2019)

[21] M. Poddar, R. Misra, Coord. Chem. Rev. 421, 22 (2020)

[22] A. Tataroğlu, A. G. Al-Sehemi, M. Özdemir, R. Özdemir, H. Usta, et al., Physica B: Condensed Matter 519, 53 (2017)

[23] E. Ozcan, G. Kesan, B. Topaloglu, E. T. Ecik, A. Dere, et al., New J. Chem. 42, 4972 (2018)

[24] M. Ucuncu, E. Karakus, M. Emrullahoglu, Chem. Commun. 52, 8247 (2016)

[25] R. Dennington, T. Keith, J. Millam, GaussView, Version 5, Shawnee Mission KS, Semichem Inc, 2009

[26] M. J. Frisch, G. W. Trucks, H. B. Schlegel, G. E. Scuseria, M. A. Robb, et al., Gaussian 09, Revision C.01, Gaussian Inc, Wallingford, CT, 2009

[27] P. W. Atkins, M. E. Hagerman, D. F. Shriver, Inorganic Chemistry, (Oxford Univ. Press, Oxford, 2010)

[28] E. H. Rhoderick, R. H. Williams, Metal-Semiconductor Contacts, (Clarendon Press Oxford 1988)

[29] H. C. Card, E. H. Rhoderick, J. Phys. D: Appl. Phys. 4, 1589 (1971)

[30] S. K. Cheung, N. W. Cheung, Appl. Phys. Lett. 49, 85 (1986)

[31] U. Akin, O. F. Yuksel, E. Tasci, N. Tugluoglu, Silicon 12, 1399 (2020)

[32] A. A. Hendi, J. Alloys Compd. 647, 259 (2015)

[33] E. Arene, J. Baixeras, Phys. Rev. B 30, 2016 (1984)

[34] A. Rose, Concepts in Photoconductivity and Allied Problems, ( Krieger Publishing Co, Huntington, N. Y., 1978) 
Figures

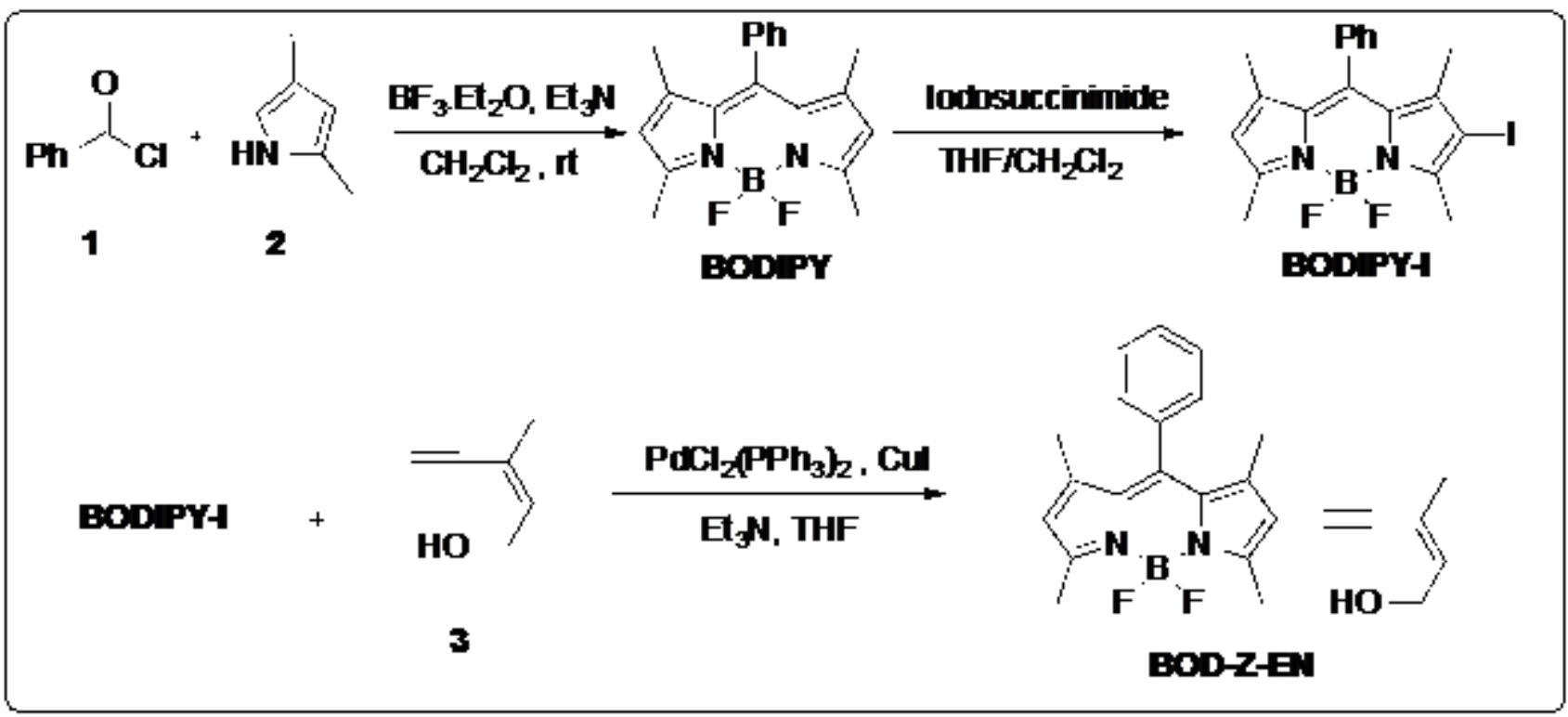

Figure 1

Synthetic route to BOD-Z-EN

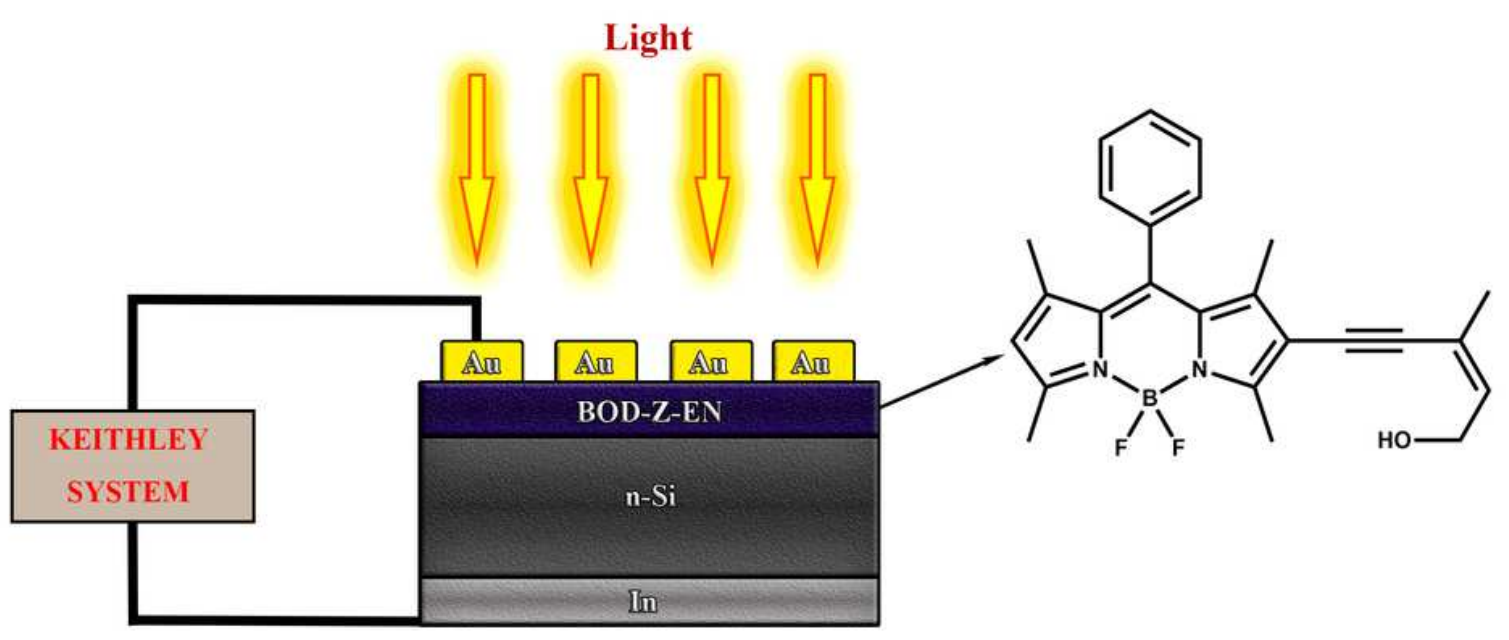

Figure 2

Schematic structure of the Au/BOD-Z-EN/n-Si/In device 


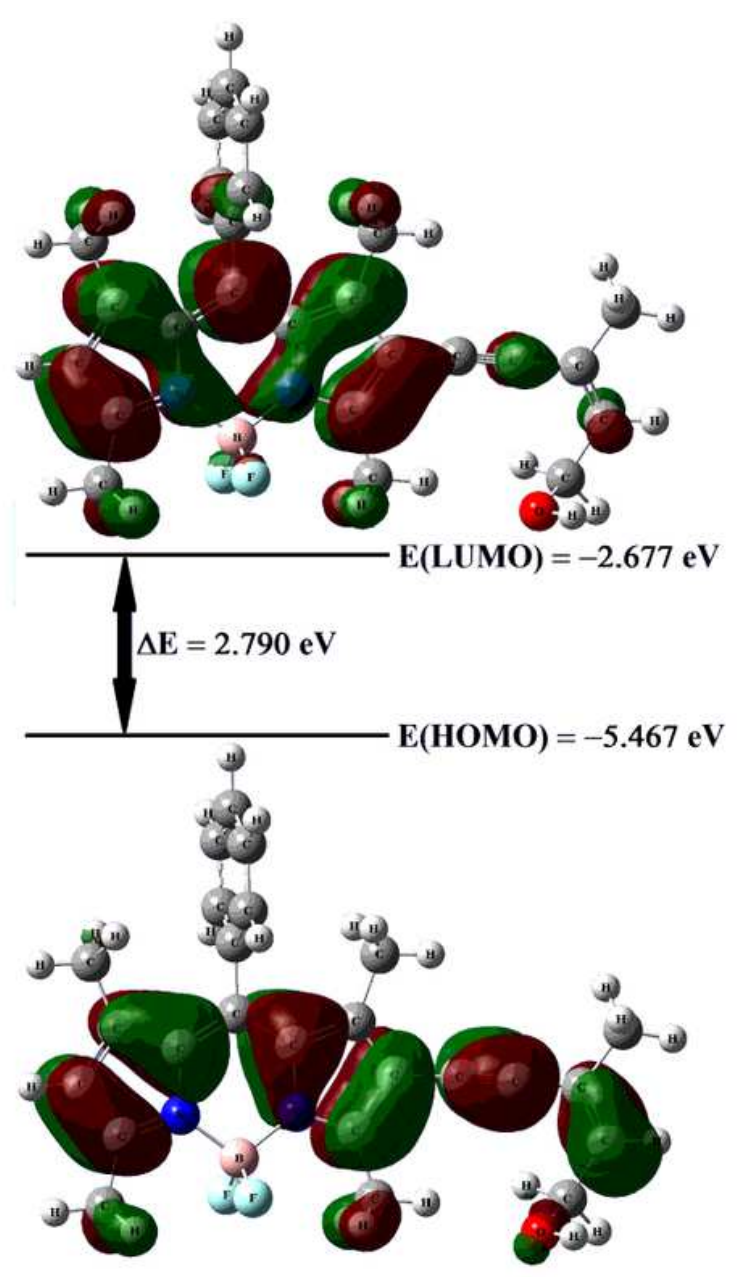

(a)

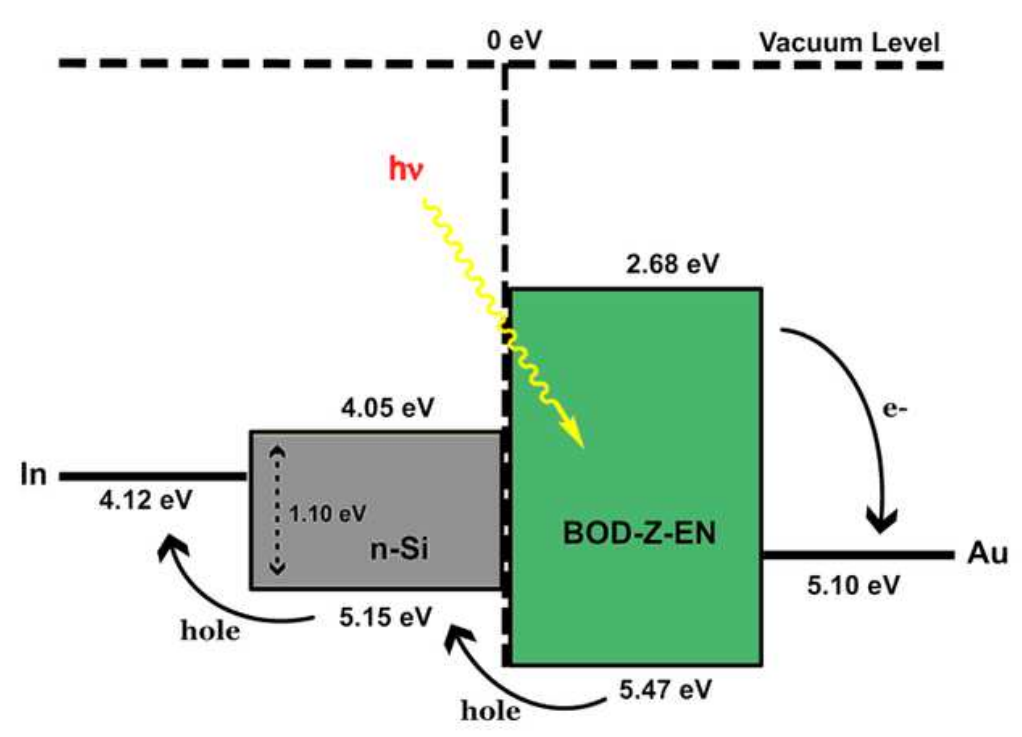

Figure 3

(a) Computed HOMO/LUMO energy levels of BOD-Z-EN (b) Energy band diagram of Au/BOD-Z-EN/n-Si/In device 


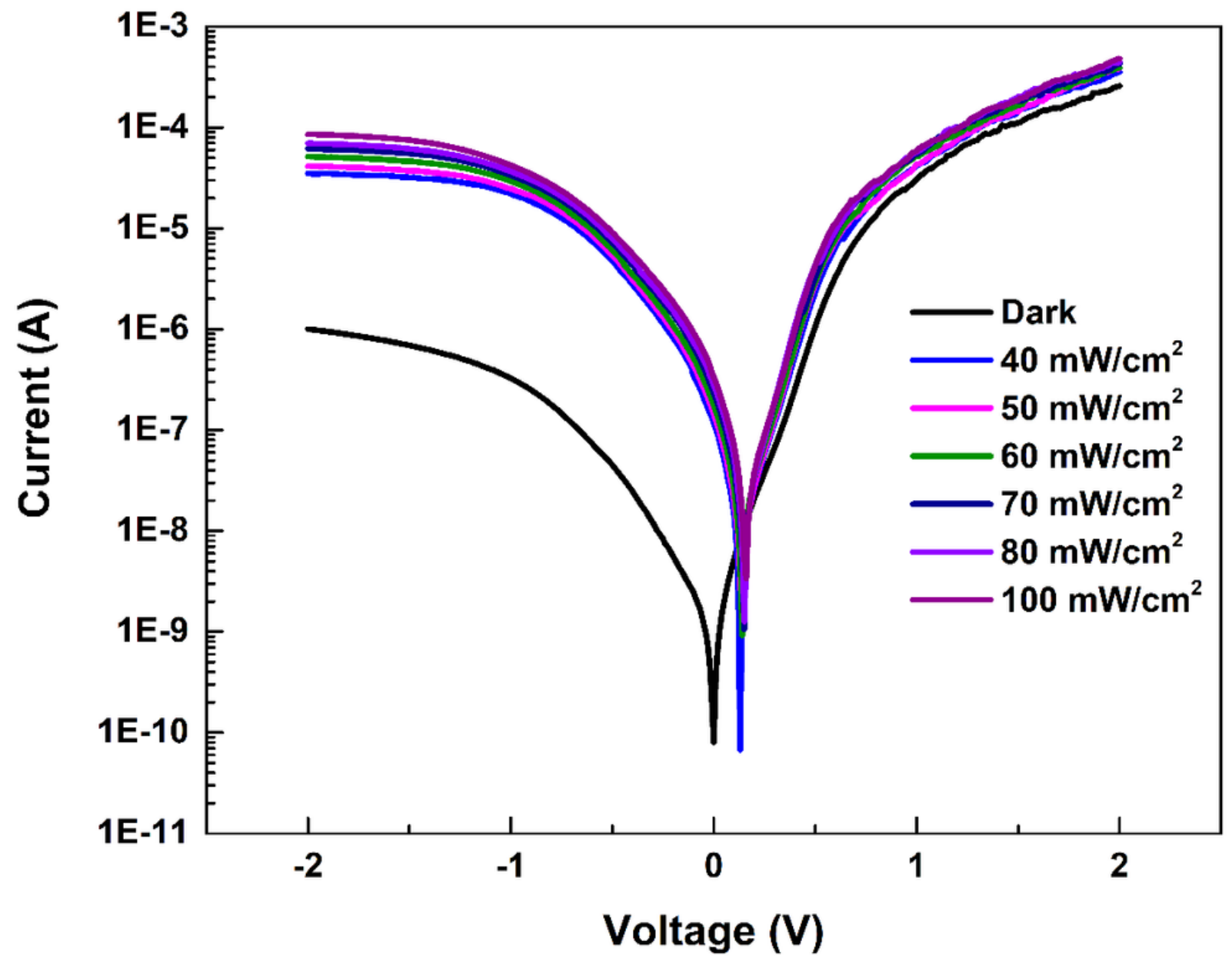

Figure 4

The forward and reverse bias the I-V characteristics of the Au/BOD-Z-EN/n-Si/In device 


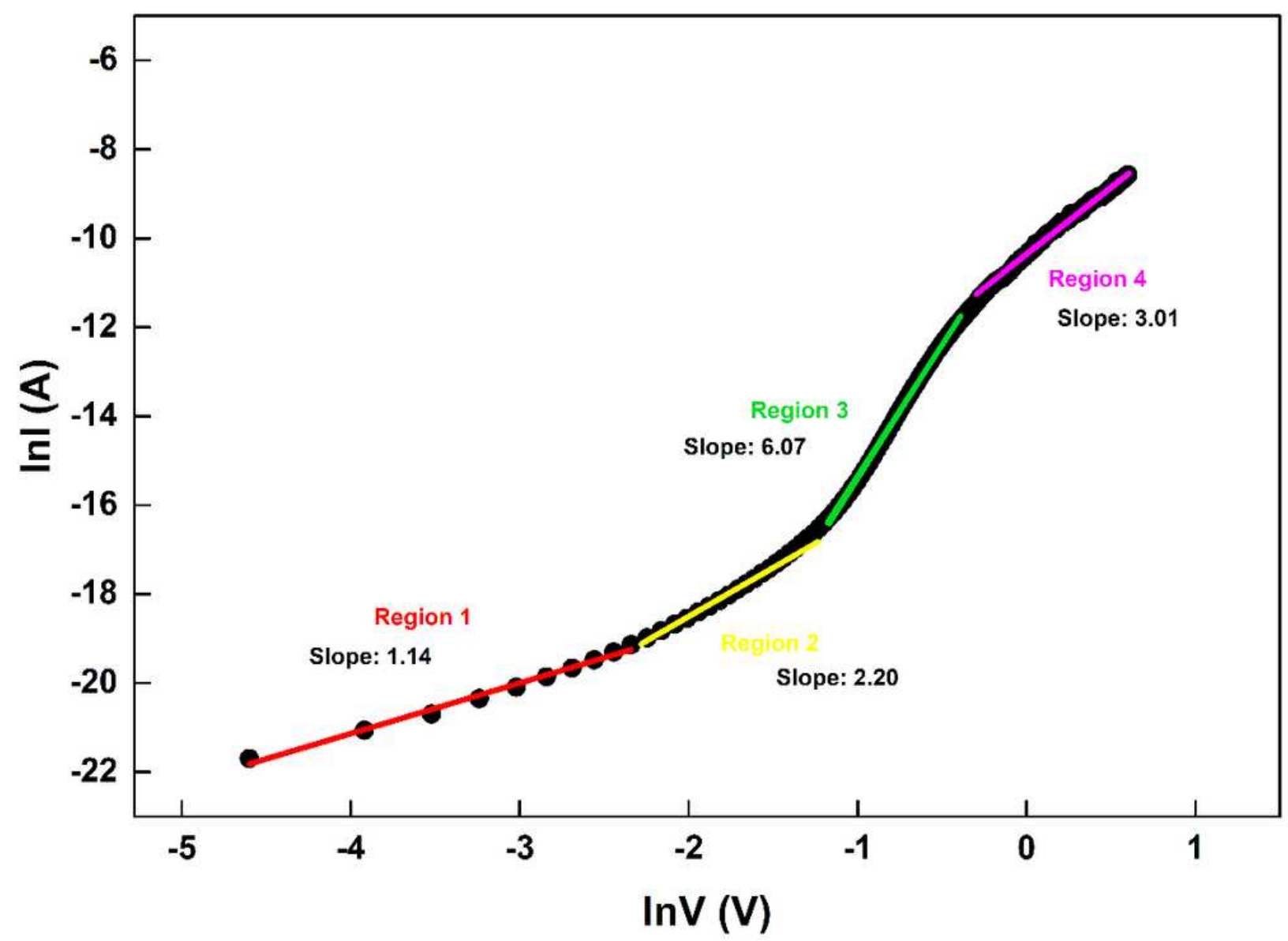

Figure 5

The $\ln (I)$ versus $\ln (\mathrm{V})$ plot of the Au/BOD-Z-EN/n-Si/In device 


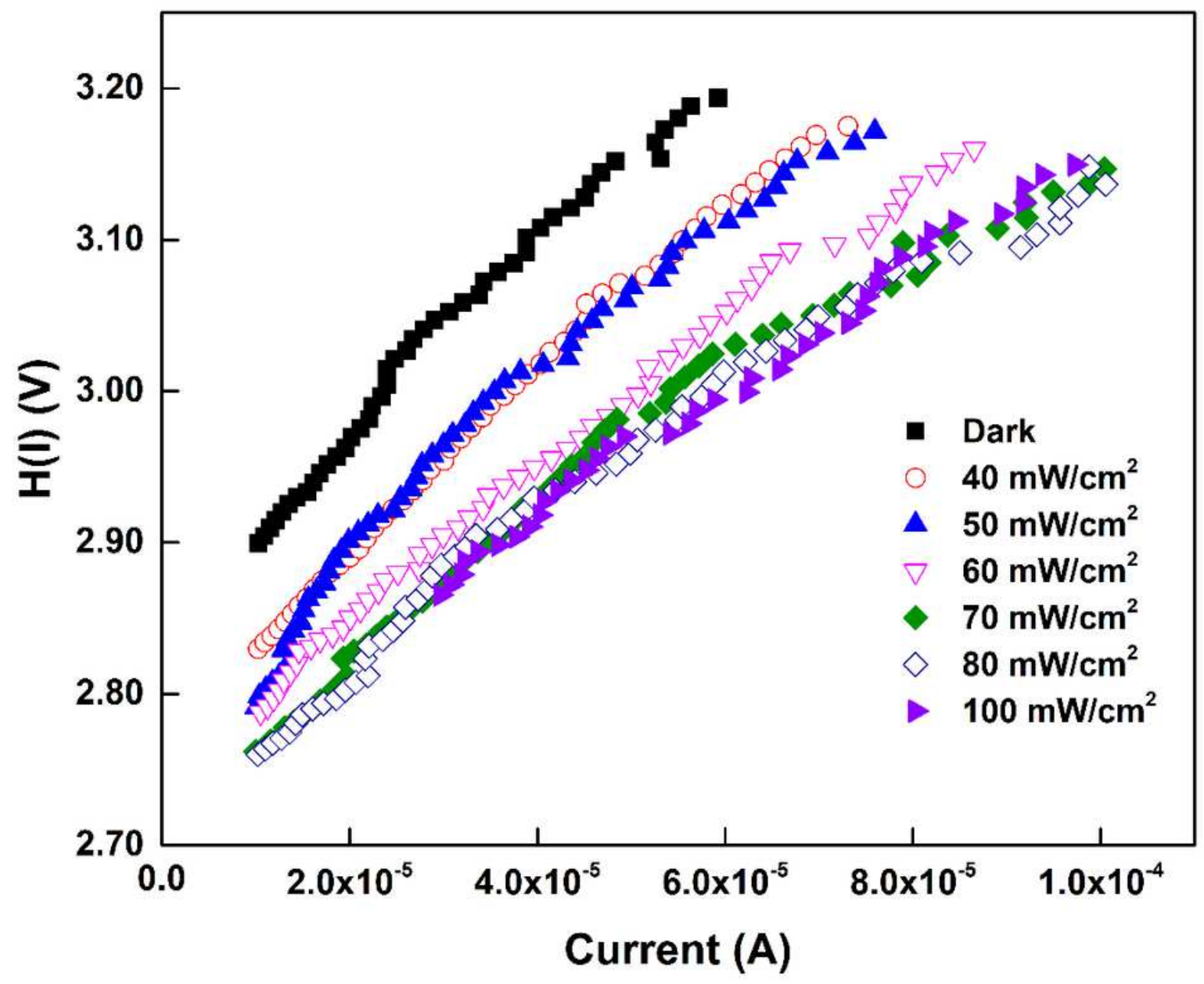

Figure 6

$H(I)$ vs I plots for Au/BOD-Z-EN/n-Si/In device 


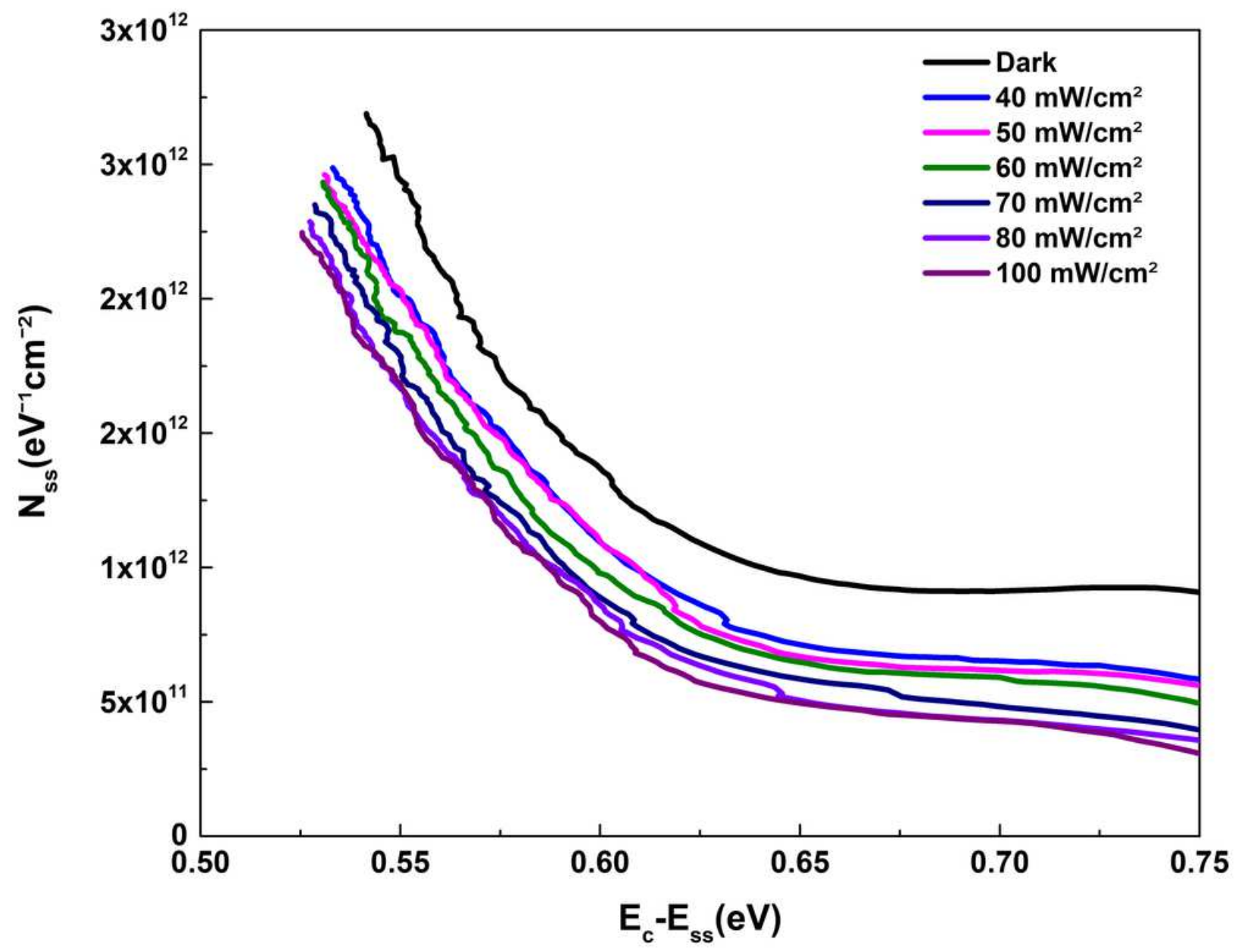

Figure 7

Nss distributions profile of the Au/BOD-Z-EN/n-Si/In diode 


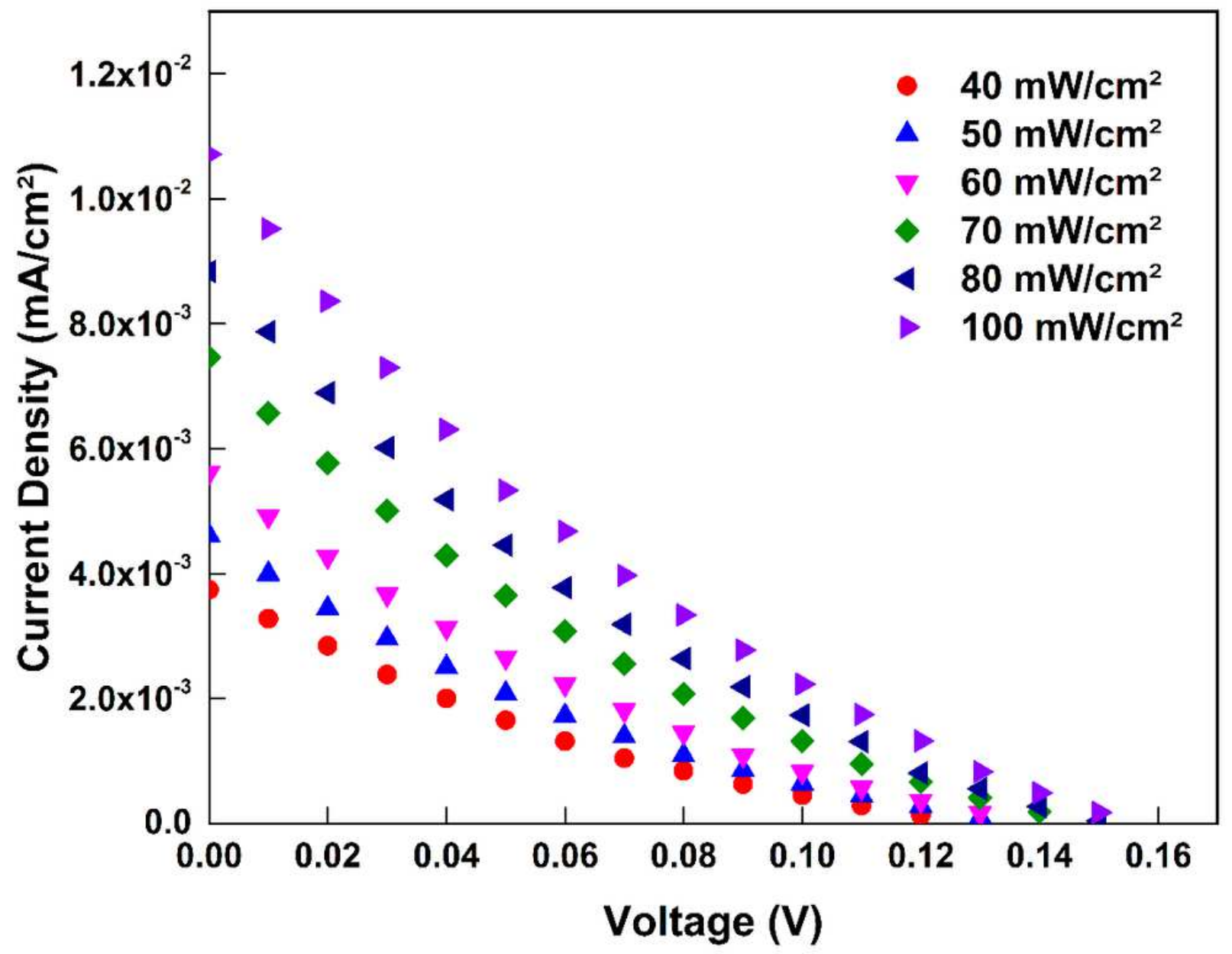

Figure 8

The current density-voltage (J-V) characteristics of Au/BOD-Z-EN/n-Si/In device in dark and under different illumination levels. 


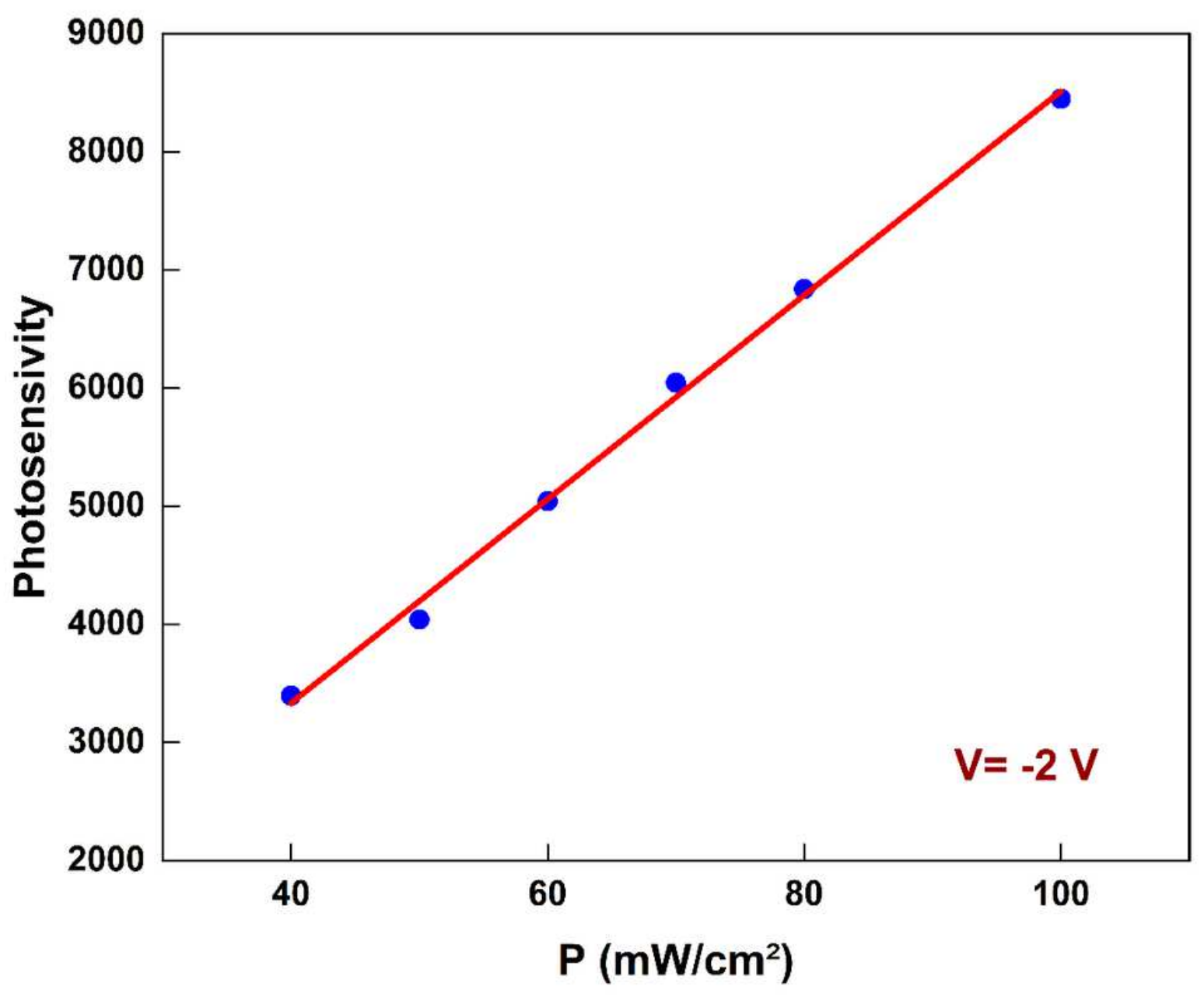

Figure 9

Plot of photosensitivity vs. P for the Au/BOD-Z-EN/n-Si/In diode. 


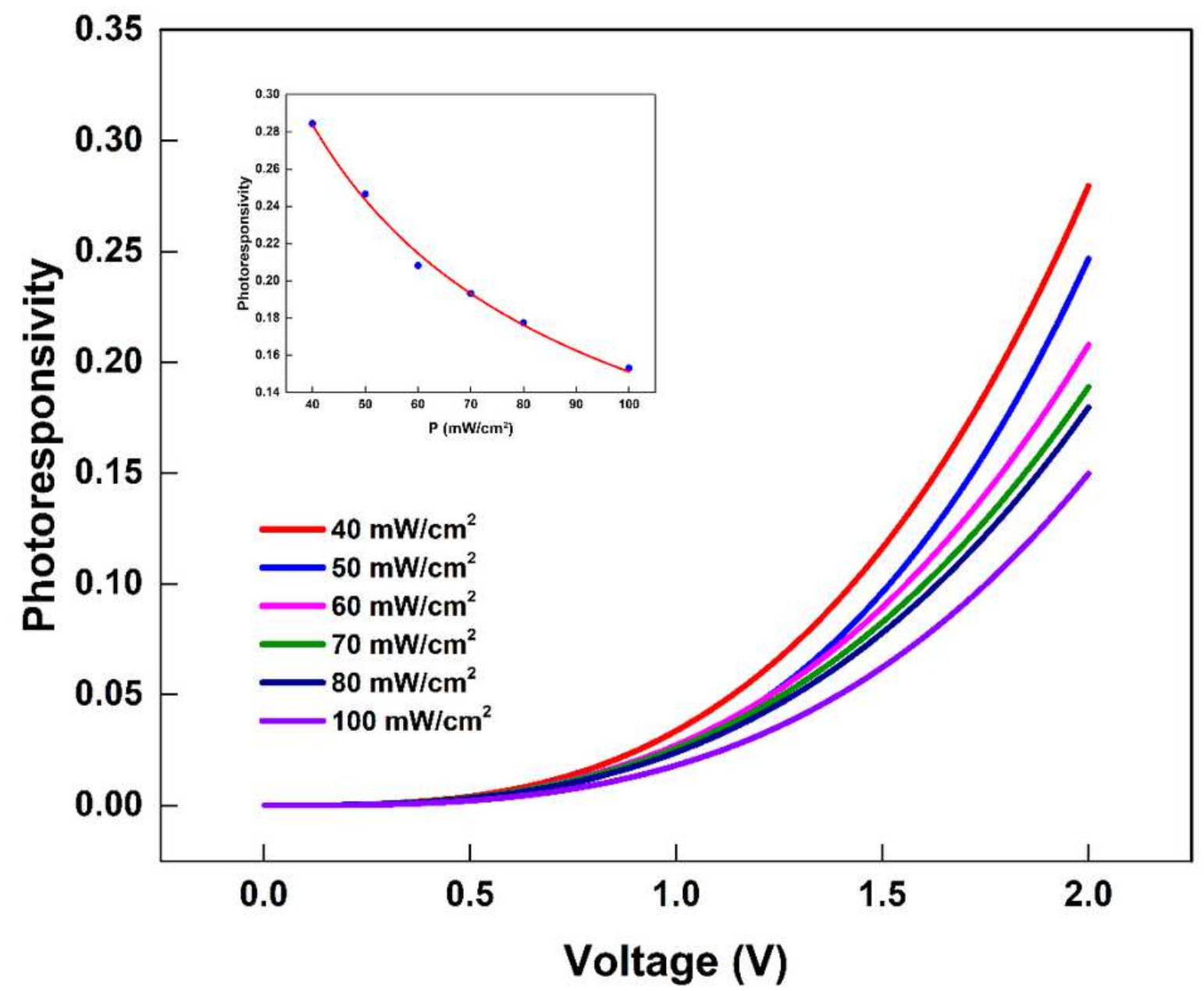

Figure 10

R-V plot of Au/BOD-Z-EN/n-Si/In Schottky diode under various illumination intensity 


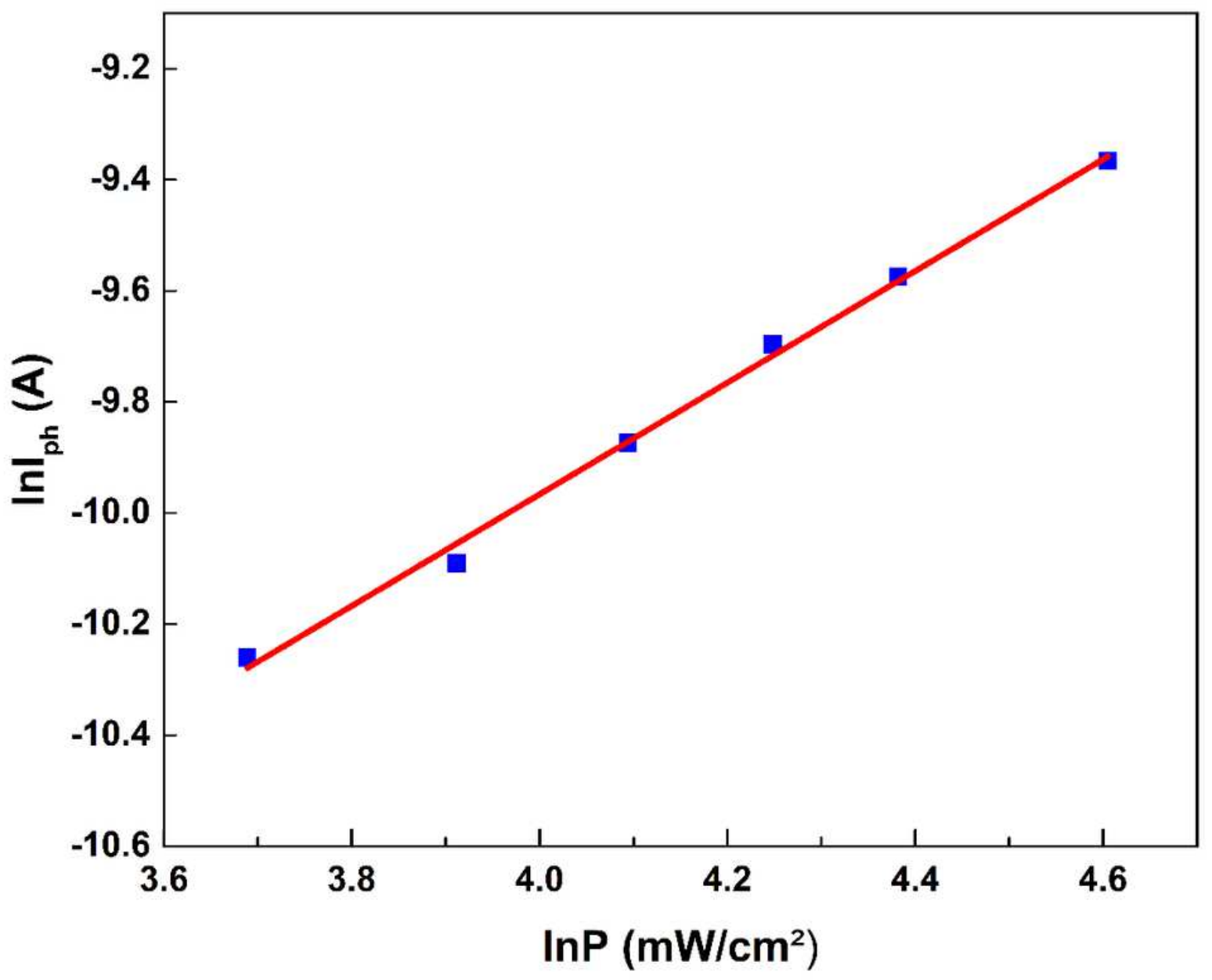

Figure 11

Inlph - InP plot of the Au/BOD-Z-En/n-Si/In diode 